\title{
Mutatio est dexterae excelsi
}

\author{
Visaugstākais man atrāvis savu labo roku! \\ (77. psalms, 11. rinda, U. Bērziņa tulk.)
}

\section{Burkard Waldis ( ${ }^{*}$ um 1490, † 1556), in Riga und in Hessen ${ }^{1}$}

\author{
Ulrich Schoenborn \\ Marburg/Lahn \\ E-Mail: uschoenborn@web.de
}

In dem nordhessischen Ort Abterode (heute: Werra-Meissner-Kreis) wurde am 13. September 1544 Burcardus Waldis, wie er sich selbst auf den Titelblättern seiner Dichtungen vorgestellt hat, als Propst und Pfarrer der evangelischen Kirchengemeinde eingeführt. Bis zu diesem Datum hatte Waldis einen bewegten und wechselvollen Lebensweg durchschritten. Seine Person verbindet in bemerkenswerter Weise Hessen und Livland, genauer Riga. Wer sich mit der livländischen Reformationsgeschichte beschäftigt, wird auf ihn als einen aktiven Protestanten der ersten Phase stoßen. So überraschend diese Entdeckung sein mag, so ernüchternd ist die Quellenlage, die viele Fragen unbeantwortet läßt ${ }^{2}$. Auch erstaunt, dass neuere Forschungsliteratur zu Leben und Werk fehlt, obwohl Burkard Waldis zu den bedeutendsten Dichtern deutscher Sprache des 16. Jahrhunderts gezählt wird ${ }^{3}$. Diese Ausgangslage rechtfertigt den Versuch, text- und autorbezogene Perspektive miteinander zu verschränken.

1 Für den Druck überarbeitet und mit Abbildungen angereichert. - Für Hinweise und Photos danke ich Frau Dr. Elisabeth Riegel (Bad Sooden-Allendorf), Frau Agnes Huck (Hessisch-Lichtenau), Herrn Gunther Rademacher (Bad Sooden-Allendorf), Pater Dr. Werinhard Einhorn OFM (Paderborn), Herrn Bernd Schmies (Münster) und Pfr. i.R. Armin Schmiedeberg (früher Abterode).

2 Vgl. Friedrich Wilhelm Strieder, Grundlage zu einer Hessischen Gelehrten- und Schriftsteller-Geschichte. Von der Reformation bis 1806 Bd. 16, hrsg. von Ludwig Wachler, Marburg 1812, 423-429; 423: „Schwerlich wird mit Nachrichten von diesem Manne ins Reine zu kommen sein."; Lutz Mackensen, Waldis in Riga, in: Zur deutschen Literatur Altlivlands, Ostdeutsche Beiträge aus dem Göttinger Arbeitskreis Bd. 18, Würzburg 1961, 59-83; 59: „Waldis in Riga: das ist ein Kapitel voller Rätsel. Sie vermehren sich, je näher man ihnen kommt.“

3 Zur Werk- und Forschungsbibliographie vgl. Ludger LieB, Erzählen an den Grenzen der Fabel. Studien zum Esopus des Burkard Waldis, Frankfurt/Main u.a. 1996, 240ff. - Die Zitate aus Burkard Waldis' Werk folgen den Ausgaben von HeInRICH KuRz (Esopus. Erster und Zweiter Teil, hrsg. von Heinrich Kurz, Leipzig 1862) und Gustav MilchsaCK (Die Parabel vom verlorenen Sohn [1527], hrsg. von Gustav Milchsack, Halle 1881). 
1. Burkard Waldis wurde zwischen 1490 und 1496 in Allendorf an der Werra (heute: Bad Sooden-Allendorf; s. Abb. 1) geboren, wo die angesehene Familie der Waldis seit dem frühen 12. Jahrhundert urkundlich nachweisbar ist. Der Name „Waldis“ (oder Waldes) muß als Hinweis auf seine Herkunft verstanden werden und verweist auf einen Nachbarort am Fluß Werra, der einst „Waldesa“ hieß und dann „Wahlhausen“. Die Waldis gehörten zu den Familien, die an der Salzgewinnung und am Salzhandel beteiligt waren. Sie waren „Pfänner“(d.h., Besitzer von Salzpfannen). Mitglieder der Familie saßen im Rat der Stadt, waren wiederholt Bürgermeister und trugen Verantwortung im Gemeinwesen. Von Beruf waren sie u.a. Zinngießer. Auf Bernhard Waldis, einen der vier Brüder, geht eine Armenstiftung zurück (1564), mit der er eine ältere „Stiftung seiner Eltern und Vorgesippten“ aufbessern wollte. Diese Einrichtung existiert bis in die heutige Zeit.

Über den Anfängen seines Lebens liegt Dunkel, weil alle Kirchenbücher, Urkunden u.a. bei der Zerstörung der Stadt Allendorf 1637 vernichtet wurden. In den historischen Quellen taucht Burkard Waldis erst 1522 auf und zwar in Riga, wo er als Angehöriger des Franziskanerordens im Dienst des aus Westfalen stammenden Erzbischofs Jasper von Linden steht. - War Waldis für den geistlichen Stand bestimmt worden? Oder hatte er zuvor einen säkularen Beruf erlernt? Evtl. in der väterlichen Werkstatt? Und war er vielleicht als wandernder Geselle nach Riga gekommen und erst dort in den Orden eingetreten? Was hat Burkard Waldis bewogen, in den Franziskanerorden einzutreten bzw. nach Livland zu gehen?

2. Vielleicht wird das Dunkel über seiner Biographie ein wenig gelichtet, wenn historische Daten über Auftreten und Profil des Franziskanerordens in Preußen und in Livland ${ }^{4}$ zusammengetragen werden. Dieser Versuch muß gewagt werden, auch wenn die Aussichten aufgrund der Quellenlage und erhaltenen Überlieferungen gering sind.

2.1. Die christlichen Missionsbestrebungen in dem genannten Gebiet reichen ins 11. Jahrhundert zurück ${ }^{5}$. Aber erst das Wirken des Ordens der Schwertbrüder und der Deutschordensritter hat die Voraussetzungen geschaffen, dass eine Infrastruktur für die Missionsarbeit vorhanden war. Feste Plätze wurden angelegt, städtische Anlagen

4 Vgl. LeOnhard Lemmens, Urkundenbuch der alten sächsischen Franziskanerprovinzen, I: Die Observantenkustodie Livland und Preußen, Düsseldorf 1913; Ders., Geschichte der Observantenkustodie Livland und Preußen, in: Beiträge zur Geschichte der sächsischen Franziskanerprovinz vom Heiligen Kreuze 6, 1913, 5-67; FerdinAND DoElle, Die Observanzbewegung in der sächsischen Franziskanerprovinz (Mittelund Ostdeutschland) bis zum Generalkapitel von Parma 1529, Münster 1918; Hans Niedermeier, Die Franziskaner in Preußen, Livland und Litauen im Mittelalter, in: Zeitschrift für Ostforschung 27, 1978, 1-31; Bernd Schmies/Kirsten Rakemann (BeARB.), Spuren franziskanischer Geschichte. Chronologischer Abriß der Geschichte der Sächsischen Franziskanerprovinzen von ihren Anfängen bis zur Gegenwart. Hrsg. von Dieter Berg, Saxonia Franciscana-Sonderband, Werl 1999.

5 Vgl. Manfred Hellmann (Hg.), Studien über die Anfänge der Mission in Livland, Sigmaringen 1989; bes. 7-36: DERS., Die Anfänge der christlichen Mission in den baltischen Ländern. 
wurden gebaut, in denen auch Klöster gegründet werden konnten. Nicht immer hat das Vorgehen der Ordensritter Zustimmung gefunden, weil die Ausbreitung des Christentums mit Gewaltanwendung verbunden war. Obwohl im Denkhorizont des Mittelalters der Kampf gegen das Heidentum als eine gerechte und von Gott gebotene Sache angesehen wurde, hat es Kritik in den eigenen Reihen gegeben. So schrieb der franziskanische Theologe Roger Bacon: „Der Glaube kam in die Welt nicht durch Waffen, sondern durch schlichtes Predigen“"6.

In Livland wurde 1202/04 der sog. Orden der Schwertbrüder gegründet, der wesentlich an Unterwerfung und Bekehrung der einheimischen Bevölkerung (Liven) beteiligt war. Nach einer verheerenden Niederlage 1236 bei Schaulen/ lit. Šiauliai hatten sich die übriggebliebenen Ritter mit dem Deutschen Orden vereinigt. Von da an war er die tragende Macht in dem neuen Staatsgebilde. Gleichzeitig beanspruchte auch der Erzbischof von Riga die geistliche und weltliche Herrschaft. So entstand ein Dauerkonflikt um Besitz und Jurisdiktion, der sich durch die Geschichte Alt-Livlands zog. Es versteht sich von selbst, dass der Orden keine untergeordnete Stellung einnehmen wollte, zumal sich die realen Machtmittel in seiner Hand befanden. Als sich aber herausstellte, dass der Orden seine Prioritäten in die Politik gelegt hatte und der ursprünglichen Aufgabe, Missionierung, nicht nachkam, war der Boden für neue Kräfte vorbereitet. „In den mittleren Jahrzehnten des 13. Jahrhunderts erlebte der Ostseeraum eine rasche Expansion der Bettelorden" ${ }^{\text {"7 }}$, die auf der Grundlage der Kreuzzugs- und Missionspolitik des lateinischen Europa agierten.

In vorderster Linie standen neben den Dominikanern vor allem die Franziskaner. Noch zu Lebzeiten ihres Ordensgründers (1181/82-1226) waren nördlich der Alpen Niederlassungen gegründet worden. 1223 entstanden in Hildesheim, Braunschweig, Halberstadt, Goslar, Magdeburg und an verschiedenen Orten in Thüringen Konvente (Erfurt, Eisenach, Gotha, Mühlhausen, Nordhausen), von wo der Orden sich nach Osten hin ausbreitete. Begünstigt wurden diese Anfänge durch die Faszination, die von Auftreten, Kleidung, Verhalten und Botschaft der „fratres minores“, „Barfüsser“ oder „Grauen Brüder“, wie man die Angehörigen der neuen Gemeinschaft nannte, ausging. M.a.W., die Spiritualität der Fransziskaner antwortete auf Zeitstimmung und Forderungen der Menschen nach Reformen ${ }^{8}$.

Um 1239 traten die ersten Franziskaner in Preußen auf und wirkten unter dem Schutz des Deutschen Ordens. Organisatorisch standen die Fratres im Nordosten in enger Verbindung mit den Konventen im Westen des Reiches. Der geographische Raum der Provinz reichte von Kiel im Norden über Riga im Nordosten bis Eger im Süden und Bremen im Westen. Das Patronat „S. Crucis“ trug die sächsische Provinz, der zweite strukturelle Zusammenschluß neben der Rheinischen Provinz des Ordens.

6 Zit. bei Niedermeier (wie Anm. 4), 4; vgl. auch William Urban, Roger Bacon and the Teutonic Knights, in: Journal of Baltic Studies 19, 1988, 363-370.

7 Anti Selart, Die Bettelmönche im Ostseeraum zur Zeit des Erzbischofs Albert von Suerbeer von Riga (Mitte des 13. Jahrhunderts), in: Zeitschrift für Ostmitteleuropaforschung 56, 2007, 475-499.

8 Vgl. die Artikel in Thomas T.Müller/Bernd Schmies/Christian Loefke (Hg.), Für Gott und die Welt. Franziskaner in Thüringen, Paderborn u.a. 2008. - Die Quellenbasis zur Geschichte des Franziskanerordens in Livland ist leider sehr schmal; s.o. Anm. 4. 
Die Zugehörigkeit zur Provinz Böhmen und Polen war nur vorübergehend. 1239 wurde das Kloster in Thorn eingerichtet. Im Laufe der nächsten Jahrzehnte kamen Klostergründungen in Kulm, Neuenburg (Kr. Schwetz), Braunsberg, Wehlau, Wartenberg, Danzig u.a. dazu. „Im Anfang des 14. Jahrhunderts gehören sämtliche preußischen Minoritenkonvente zur Sächsischen Provinz"c9. Um die Mitte des Jahrhunderts war die Provinz in 12 Kustodien eingeteilt und zählte 95 Konvente. Preußen war die zwölfte Kustodie.

Zwischen Ritterorden und Franziskanern (wie auch den anderen Bettelorden) herrschte gutes Einvernehmen. Das lag einmal an dem gemeinsamen Herkommen: Deutschland. Zum anderen kam dem Orden das Armutsprinzip zugute. Denn der Deutsche Ritterorden war bestrebt, möglichst wenig Grundbesitz in die Verfügung der Klöster gelangen zu lassen. Darum wurden die besitzenden Orden (Praemonstratenser, Benediktiner u.a.) weniger berücksichtigt, dagegen die Bettelorden, vor allem die Franziskaner, favorisiert, die in Seelsorge und Predigt ihre Hauptaufgaben sahen. Folglich haben sie das äußere Erscheinungsbild der Mission im Baltikum geprägt. Die Akzeptanz in der Bevölkerung resultierte nicht zuletzt aus der franziskanischen Opposition gegen Verbürgerlichung, Klerikalisierung und Anpassung an weltliche Strukturen. Auch dadurch wuchs die Reputation der Franziskaner, dass sie sich um die regionalen Sprachen bemühten und Gegenden aufsuchten, die von den Rittern gemieden wurden.

Nach Riga kamen die ersten Franziskaner aus Lübeck im Jahre 1238. Ihnen wurden durch den Rat der Stadt alle Wege zur Klostergründung (1258) geebnet ${ }^{10}$. 1348 fielen fast drei Viertel der Brüder der Pest zum Opfer. Schwerwiegender war jedoch, dass der Orden vom Zeitgeist eingeholt wurde. „Die Anpassung an die allgemeine spätmittelalterliche Realität des Ordenslebens wurde buchstäblich auf Kosten des Ordensprofils erkauft"11. Der Konvent in Riga machte in der Folgezeit eher durch den Verfall der Ordensdisziplin und Auseinandersetzungen mit der Stadt von sich reden. Missionarische Impulse gingen kaum von ihm aus. Anlaß zu Klagen gab das Zusammenleben der Fratres und wirtschaftliche Mißstände. Der Guardian hatte Besitztümer des Ordens veruntreut, Schulden gemacht und willkürliches Verhalten an den Tag gelegt. Diese Umstände stießen auf Widerstand in den eigenen Reihen und weckten Veränderungswünsche. Unter Heinrich Holst, Frater im St. Katharinenkonvent von Riga wurden seit 1436 Reformen konzipiert. Holst schloß sich dabei der Ordenspolitik des Provinzials der sächsischen Provinz, Matthias Döring, an. U.a. wurde der Konvent gegenüber dem Vorsteher gestärkt und ein strenges Kontrollsystem im Wirtschaftsbereich eingeführt. Außerdem wurde die Verwaltung des Klostergutes dem direkten Zugriff der Brüder entzogen. Auch förderte der Provinzial

9 Niedermeier (wie Anm. 4), 10.

${ }^{10}$ Vgl. Autbert Groeteken, Die Franziskaner in Riga, in: Beiträge zur Geschichte der sächsischen Franziskanerprovinz vom Heiligen Kreuze 3, 1910, 76-92; SElarT (wie Anm. 7), 485f.

${ }^{11}$ Schmies, in: Müller/Schmies/LoefKe (Hg.) (wie Anm. 8), 47. 
die Erneuerung durch personelle Auswechslung. Umstrittene Fratres wurden versetzt und untadelige Brüder aus anderen Kustodien nach Riga gesandt ${ }^{12}$.

Um die Mitte des 15. Jahrhunderts drang vom Westen her eine ordensinterne Reformbewegung vor, die sog. „Observanz“. Aber auch nachdem die internen Kontroversen „,beigelegt“ waren, blieben das franziskanische Selbstverständnis und die Auslegung der Tradition umstritten. Es ging darum, die „conventualitas“ zur „,regularis observantia“ zurückzuführen. Die gegensätzlichen Meinungen konzentrierten sich in zwei Lagern. „Der wesentliche Unterschied zwischen Observanten und Konventualen im Minoritenorden lag (...) in der Stellung zur Ordensarmut: die Observanten hielten fest an der Eigentumslosigkeit in communi und verzichteten auf feste Einkünfte und liegende Güter, während die Konventualen gemeinsamen Besitz, Renten und Liegenschaften zuließen“13. Die kirchenpolitischen Aktivitäten und Interessenverschiebungen im Orden hatten zu einer ,geistlichen Verwahrlosung“ beigetragen und indirekt auch das Anwachsen von antiklerikalem Unmut gefördert. Gegen diese Entwicklung wandte sich die Reformbewegung innerhalb des Ordens, die sog. Observanz. Sie suchte durch Rückgang auf das Armutsideal das Ordensprofil neu zu definieren. Ausgehend von Klöstern in Italien und Frankreich hat sich die Bewegung auch in den Ordensprovinzen jenseits der Alpen ausgebreitet. Mit der Einführung ihrer Interpretation der Ordensregel im Brandenburger Franziskanerkloster 1427/28 hatte die Observanz in der Saxonia einen ersten Erfolg. Ein Kerngebiet der Observanz innerhalb der Saxonia wurde die Custodie Thüringen mit Erfurt als Zentrum theologischer Ausbildung. Dort kam es dann auch zu Zusammenstößen zwischen den „Observanten“ und den sog. „Konventualen“, die um ihre örtlichen/ regionalen Privilegien fürchteten. Der Provinzial M. Döring reagierte auf die ordensinternen Herausforderungen, indem er ein eigenes Reformmodell „sub ministris“ zu realisieren versuchte, in dem Armut und Gehorsam im Einklang stehen sollten. Dieses Reformmodell „,von oben“, dann als „Constitutiones Martianae“ formalisiert, existierte bis zur organisatorischen Spaltung des Ordens neben dem radikalen Ansatz.

Die franziskanische Ordensprovinz Saxonia befand sich zu Beginn des 16. Jahrhunderts in einer komplizierten und verfahrenen Situation. Richtungsgegensätze, interne Kontroversen und äußere Einflussnahmen kennzeichneten die Erscheinung des Ordens. Dem Wirken der Observanten ist es allerdings zu verdanken, dass die Glaubwürdigkeit des Ordens nicht völlig destruiert wurde und die Klagen

${ }^{12}$ Dazu ausführlich Petra Weigel, Ordensreform und Konziliarismus. Der Franziskanerprovinzial Matthias Döring (1427-1461), Frankfurt a.a. 2005, 54ff. Ferner: BERND Schmies, Ludwig Henning. Provinzialminister 1507 bis 1517, in: Dieter Berg (Hg.), Management und Minoritas. Lebensbilder sächsischer Franziskanerprovinziale vom 13. bis zum 20. Jahrhundert, Saxonia Franciscana/Beiheft 1, Kevelar 2003, 88-143.

${ }^{13}$ Heribert Holzapfel, Handbuch der Geschichte des Franziskanerordens, Freiburg 1909, 81. Als beide Lager immer stärker miteinander konkurrierten, eskalierte der Streit, so dass es $1517 \mathrm{zu}$ einer organisatorischen und strukturellen Trennung kam (vgl. 147ff.; 298ff.). Vgl. „http://de.wikipedia.org/wiki/Franziskaner“",,http://de.wikipedia.org/wiki/ Minoriten", http://de.wikipedia.org/wiki/Armutsstreit“. (Zugriff 31.05.2008). Ferner: Walter Ziegler, Die Franziskaner-Observanten, in: Friedhelm JürgensmeIER/Regina Elisabeth SchwerdtFeger (Hg.), Orden und Klöster im Zeitalter von Reformation und katholischer Reform 1500-1700, Bd. 3, Münster 2007, 163-214; bes. 178ff. 
zurückgingen. 1463 übernahmen die Observanten im Rigaer Konvent die Führung. Seit dem Ausgang des 14. Jahrhunderts wurden verstärkt Schulen eingerichtet. Auch wurde angeordnet, dass den Gemeinden in der Volkssprache zu predigen sei bzw. die Hilfe von Dolmetschern in Anspruch genommen werden solle. Es ist keine Frage, dass die Sympathie der Bevölkerung sich den Observanten zuneigte und deren Aktivitäten gefördert wurden.

In Livland sind dem Wirken der Observanten die Verbreitung des erneuerten Armutideals und die Gründung von Klöstern in Dorpat/estn. Tartu, Fellin/ estn. Viljandi, Lemsal/lett. Limbaži, Hasenpoth/lett. Aizpute, Kokenhusen/lett. Koknese u.a. zu verdanken. Zusammen mit dem Kloster in Riga bildeten sie die „Custodia Livoniae“. Als der Deutsche Orden jedoch politische Relevanz und militärische Macht verlor, schwand auch das Gewicht der Franziskaner-Observanten. Weitere Gründe für den Bedeutungsverlust des Ordens sind einmal die Anlehnung an die (zweite) politische Macht, den Erzbischof von Riga, bzw. die Verdrängung der Ordensideale. Vor allem aber begannen sich Ideale und Zielvorstellungen in der Gesellschaft zu verändern. In dem Maße, wie die Städter an Selbstbewußtsein gewannen, lehnten sie religiöse Sondergemeinschaften ab. Sie erwarteten „Kleriker als Bürger" (Bernd Moeller). Dass der Aktionsradius des Ordens schließlich durch das Vordringen der Reformation eingeengt wurde, war eine zwangsläufige Folge.

2.2. In vorreformatorischer Zeit hat es einzelne Minoriten gegeben, deren Auftreten im historischen Gedächtnis festgehalten wurde. Sie geben, auch wenn ihr Beispiel nicht generalisiert werden darf, Einblick in die von Umbrüchen, Ambivalenzen und hochgespannten Erwartungen geprägte Zeit.

Um 1500 starb in einem Eisenacher Kloster der Franziskaner Johann von Hilten $^{14}$ nach fast 25 Jahren Haft (1477-1500). Vor seinem Tode bat er die Brüder um Verzeihung für seine Taten, sofern diese Ärgernis verursacht hatten; seine theologisch-eschatologischen Diskurse wollte er jedoch nicht widerrufen. Bevor er inhaftiert wurde, hatte er sich in Riga (seit 1463) und vor allem in Reval bzw. Dorpat aufgehalten. Hilten soll in Thüringen geboren sein. Der Sprache nach stammte er jedoch aus dem Niederdeutschen ${ }^{15}$. Er hatte in Erfurt studiert und den philosophischen Magister erworben. Allerdings sucht man seinen Namen in den Universitätsmatrikeln vergeblich. In den Franziskanerorden muß er vor 1462 eingetreten sein. Denn im August jenes Jahres kam in Celle das Provinzialkapitel der sächsischen Observanten zusammen und bestellte eine Delegation für Livland. Durch den Vikar der sächsischen Provinz, Henning Sele, sind mehrere Brüder entsandt worden, um Reformen in den Klöstern durchzusetzen. Denn Klagen über den Zustand der Klöster waren seit

${ }^{14}$ Vgl. LeOnid Arbusow JR., Die Einführung der Reformation in Liv-, Est- und Kurland, Leipzig 1921/Neudruck Aalen 1964, 160ff.; Отто Clemen, Schriften und Lebensausgang des Eisenacher Franziskaners Johann Hilten, in: Zeitschrift für Kirchengeschichte XLVII, NF X, 1928, 402-442; Leonhard Lemmens, Der Franziskaner Johannes Hilten († um 1500), in: Römische Quartalschrift 37, 1929, 315-347; PAul JoHANSEN, Johann von Hilten in Livland. Ein franziskanischer Schwarmgeist am Vorabend der Reformation, in: ARG 36, 1939, 24-50.

${ }^{15}$ Hilten ist eine Ortschaft im Kreis Lingen. 
langem aktenkundig. Der Gruppe gehörte auch Johann von Hilten an ${ }^{16}$. Er wird den Auftrag erhalten haben, im Geist der Observantenbewegung in Reval zu predigen und für den Neubau von Franziskaner-Klöstern zu werben.

Während seines Aufenthaltes in Reval hat Hilten aufgrund seiner rhetorischen Talente schnell eine Anhängerschar um sich gesammelt, die ihm blind ergeben war. Auch hatte er exzellente Verbindungen zu einflußreichen Mitgliedern im Rat der Stadt geknüpft und wahrscheinlich auch zum Deutschen Orden. Die Zeitumstände (Pest, Endzeitstimmung, Ängste, Konflikte zwischen den politischen Lagern u.a.) ließen ihn zu einem „Bußprediger mit reformatorischen Tendenzen“"17 und asketischen Forderungen werden. Die biblischen Wurzeln seiner Predigt lagen in den apokalyptischen Schriften (Daniel, Offenbarung des Johannes), die er für seine Zeit aktualisierte. Sein Drang nach Macht und Einfluß brachte ihn vor allem mit den führenden Schichten der Stadt zusammen. Hiltens Eintreten für eine Reform der Kirche fand viel Zustimmung. Dass seine auf den apokalyptischen Schriften der Bibel beruhende Predigt auch indirekte Kritik am kirchlichen System enthielt, wird erst bei gründlichem Nachdenken erkannt worden sein. Ein Revolutionär war Hilten aber nicht. Sein Wirken in Reval hat jedoch zu Polarisationen geführt. So war er in einen komplexen Prozeß verwickelt, in dem einige seiner Anhänger und deren Gegner lange Jahre um die Besitzrechte an zwei Immobilien stritten ${ }^{18}$. Als er sich nicht mehr in Reval halten konnte, weil er die Unterstützung im Rat und beim Deutschen Orden verloren ${ }^{19}$ hatte, ist er nach Dorpat ausgewichen und hat im dortigen Kloster für gewisse Zeit eine Rolle gespielt (1472 Lektor) ${ }^{20}$. Seine theologisch-eschatologische Radikalität (Prophezeiungen, visionäre Schwärmereien, Schilderungen des Jüngsten Tages u.a. $)^{21}$ und sein Eifer für die Ordensregel haben dann die Ordensoberen bewogen, ihn aus Livland abzuziehen und in ,geistliche Haft“ zu setzen. Immerhin ist sein Beispiel so bekannt geworden, dass Luther ${ }^{22}$ es für wichtig hielt, über ihn

16 Vgl. Lemmens (wie Anm. 4), 33, Nr. 109.

17 JOHANSEN (wie Anm. 14), 49.

${ }^{18}$ Einzelheiten dazu bei JoHANSEN (wie Anm. 14), 29ff.

${ }^{19}$ Der Ordensmeister Johann Waldhaus von Heerse, dessen Zentralisierungstendenzen Hilten unterstützte, war von Gegnern innerhalb des Ordens 1471 gestürzt worden.

${ }^{20}$ Ein später (wahrscheinlich 1494) formuliertes Gebet hält im Rückblick Anfeindungen und Verfolgungen durch den eigenen Orden fest; zitiert bei Lemmens (wie Anm. 14), $344 f$.

${ }^{21}$ Seine Schriften sind als cod. Pal.lat. 1849 in der Vaticana vorhanden: „Johannes Hiltenius, Opera omnia, quae iam reperiri possunt". Vgl. die detaillierte Deskription von Lemmens (wie Anm. 14), 323ff.

${ }^{22}$ Als Luther 1498 bis 1501 in Eisenach zur Schule ging, muß er den Namen „Johannes von Hilten" gehört haben (vgl. WA Tischreden Bd. III, 621). Dreißig Jahre später, auf dem Rückweg vom Marburger Religionsgespräch, erinnert er sich in Eisenach wieder daran. Er bittet darauf Friedrich Myconius (bis 1524 Franziskaner, dann Pfarrer in Gotha), über Hilten Nachforschungen anzustellen. Auch Melanchthon ist in diesen Vorgang einbezogen. Vgl. Luther, Briefwechsel 5, Nr. 1480: Luther an Friedrich Myconius in Gotha (17. Oktober 1529); Nr. 1501: Friedrich Myconius an Luther (2. Dezember 1529). In seiner Antwort berichtet Myconius über seine Erkundigungen, u.a. referiert er ein Gespräch mit einem Ordensbruder aus Langensalza, der die letzten Tage Johann von Hiltens in Eisenach erlebt hatte. Dazu vgl. Clemen (wie Anm. 14), 402ff.; bes. 408; 
Erkundigungen einzuziehen. - Johann von Hilten ist ein typisches Beispiel für den geistigen Umbruch um 1500. Er vertritt eine apokalyptische Perspektive, die im Mittelalter in vielen religiösen Gemeinschaften Anhänger gefunden hatte.

2.3. Nicht nur in der Observantenbewegung haben sich die Franziskaner engagiert. Im 15. Jahrhundert müssen sie sich zu einer Stütze der geistlichen Macht in Livland entwickelt haben. Damit verbunden war ohne Zweifel ein Zuwachs an Wohlstand und Macht. Es wundert also nicht, dass Teile des Ordens mit den Bischöfen die Ablehnung reformatorischer Veränderungen betrieben. Sie stellten ihre Agitation in den Dienst des Status quo. So hat der Franziskaner Thomas Rehberg im Einverständnis mit dem Erzbischof von Riga die Bannbulle gegen Luther öffentlich bekannt gemacht, kaum dass der Beschluß dazu 1523 auf dem Prälatentag zu Ronneburg/lett. Rauna gefaßt worden war. Diese Einmischung in das politische Tagesgeschehen kostete den Orden viel Sympathie in der Bevölkerung. Im Zusammenhang mit gewalttätigen Übergriffen auf die Klöster (u.a. 1523 in Hasenpoth/lett. Aizpute) und Mönche wurde der Rigaer Konvent 1524 vom Rat der Stadt geschlossen, und die Franziskaner wurden ausgewiesen.

Als der Sturm gegen die Franziskaner in Riga ausbrach, hat Thomas Rehberg den Orden verlassen ${ }^{23}$, ob durch Versprechungen verleitet oder aufgrund von aggressivem Druck, kann nicht eindeutig geklärt werden. Er widerrief alles, was er bisher gegen den reformatorischen Aufbruch und Luther gesagt hatte. Auch trat er als Prediger des Evangeliums auf. Sein Fall erregte beträchtlichen Ärger und Aufsehen und führte bei den Franziskanern zu Verhärtungen. Da er aber seine alten Gewohnheiten und Denkweisen nicht so einfach hat ablegen können, schickte ihn die Bürgerschaft über Lübeck auf die Universität Wittenberg zu einem Ergänzungsstudium (um „die evangelische Sache zu hören und zu erlernen“). Am 11. August 1523 wurde er immatrikuliert und sogleich in das Studentenleben eingeführt. Doch kam der ,weltfremd gewordene alte Mann" mit der neuen Umgebung nicht zurecht und brach nach einem Monat das Experiment $a b^{24}$. Auf dem Rückweg in die livländische Heimat kehrte er im Franziskanerkloster zu Lüneburg zur katholischen Kirche zurück.

2.4. Aus diesen historischen Streiflichtern lassen sich keine Schlußfolgerungen für die Biographie von Burkard Waldis ableiten. Allerdings ist es statthaft, Vermutungen zu äußern. So kann nicht bezweifelt werden, dass die Kunde von der franziskanischen Observantenbewegung im hessischen Umfeld des Burkard Waldis nicht verborgen geblieben ist. Das Gebiet der Saxonia S. Crucis und ihr Einfluss reichten weit über das Gebiet des heutigen Thüringen hinaus. Und vom westlichen

Lemmens (wie Anm. 14), 318ff. Aufgrund dieser Aussage kann es als gesichert gelten, dass Hilten weder exkommuniziert noch konvertiert, noch ermordet worden ist. Wenn er bisweilen in älterer Literatur als „Vorläufer" der Reformation geschildert wurde, geschah das aus Unkenntnis der Quellenlage bzw. aus ideologischem Antrieb. Vgl. ferner ZIEGLER (wie Anm. 13), 186ff.: Franziskaner und Lutherische Bewegung.

${ }^{23} \mathrm{Zu}$ dieser Episode vgl. ArbusOw JR. (wie Anm. 14), 258f.; $267 \mathrm{f}$.

${ }^{24}$ „Die ungewohnte Kost, der übermässige Fleischgenuss anstatt der bisherigen beobachteten Fastenzeiten machten ihn magenkrank; dann stellten sich Gewissensbisse über den Abfall ein“" (Arbusow JR, [wie Anm. 14]), 268. 
Teil der Saxonia hat es immer eine Marschrichtung gen Osten gegeben. Möglicherweise hat das Beispiel Johann von Hiltens die Runde gemacht. Und dass Waldis über besondere intellektuelle (rhetorische und literarische) Talente verfügte, konnte er bald unter Beweis stellen. Sprachkompetenz sowie historische und theologische Kenntnisse lassen erkennen, dass Waldis eine gelehrte Ausbildung genossen bzw. eine hohe Schule besucht haben muß (vgl. Esopus IV 23). Immerhin gab es seit dem 14. Jahrhundert in Allendorf in Verbindung mit der Pfarrkirche St. Crucis eine Lateinschule. Vielleicht hat er das Bildungszentrum der Franziskaner in Thüringen, Erfurt, besucht. Allerdings stand die Universität Erfurt der Observanz eher kritisch gegenüber, der wiederum Reserven gegenüber dem klassischen scholastischen Studienbetrieb nachgesagt wurden. Hingewiesen sei noch auf ein anderes Detail. Denkbar ist auch eine Verbindung nach Eisenach. Dort besaßen die Franziskaner mehrere Niederlassungen. Zwischen Allendorf und Eisenach gab es insofern Beziehungen, als Landgraf Ludwig von Hessen dem franziskanischen Katharinenkloster in Eisenach die St. Crucis-Kirche von Allendorf als Allod geschenkt hatte.

Das nahe gelegene Reichenbach (heute: Stadtteil von Hessisch Lichtenau) wurde 1207 aufgrund einer Schenkung eine der ersten Niederlassungen des Deutschen Ordens im Deutschen Reich. Die Präsenz des Ordens in der Region wurde von Thüringen aus unterstützt. Als Ordensniederlassung verlor Reichenbach nach einem Jahrhundert seinen Rang an Marburg als Sitz der Landkomturei ${ }^{25}$. Der Deutsche Orden hatte in Allendorf umfangreiche Besitztümer. Daher waren Waldis „die Brüder des Deutschen Hauses Marburg sicher von Jugend an vertraut, wenn sie in der Stadt erschienen, um vor Ort ihre Angelegenheiten bezüglich des dortigen Ordensbesitzes zu regeln“"26.

Erwähnenswert sind auch die nachweisbaren Verbindungen zwischen Allendorf und Riga. Anfang des 16. Jahrhunderts besaß ein Allendorfer Bürger in Riga ein Haus. Er ist auch in die Würde des Bürgermeisters aufgestiegen. Im Dom wurde zu seinem Gedächtnis eine Plakette angebracht. Ferner hat ein in Riga ansässiger Mann aus Allendorf bis weit in das 16. Jahrhundert eine Pension für seine Tätigkeit als Salzsieder bezogen.

3. $\mathrm{Zu}$ Beginn des 16. Jahrhunderts befand sich Alt-Livland in gärender Aufbruch- und Umbruchstimmung (s.o.), die sich über vielerlei Stationen vorbereitet hatte. Spannungen zwischen dem Erzbischof und dem Deutschen Orden bestimmten jetzt die Tagesordnung. Dazu traten die Emanzipationsbestrebungen der Städte. Gedanken der Reformation hatten sich auch in Livland ausgebreitet und vor allem in den Städten Zustimmung gefunden. 1522 hatte Andreas Knopken mit seinen 24 Thesen einen markanten Anfang gesetzt. Im selben Jahr schrieb der Stadtsyndikus

${ }^{25}$ Vgl. Reichenbach. Kloster- und Deutschordenskirche, Große Baudenkmäler Heft 531, München/Berlin 1998; VEREIN FÜR HESSISCHE LANDESGESCHICHTE. ZwEIGVEREIN Hessisch-Lichtenau (Hg.), 1207 Reichenbach 2007, Kassel 2007.

${ }^{26}$ Agnes Huck, Persönlichkeiten der Region und ihre Beziehung zum Deutschen Orden, in: Verein für Hessische Landesgeschichte. Zweigverein Hessisch Lichtenau (HG.), 1207. Reichenbach 2007, 82. 
von Riga, Johannes Lohmüller, an Luther, Livland sei eine „candidata verbi fidei“ und bat um geistliche Unterstützung. Luther antwortete 1523 mit seinem Sendbrief an die Christen in Riga, Reval und Dorpat (WA XII, 143-150) und ließ im Jahr darauf eine Auslegung des 127. Psalms folgen (WA XV, 360-379). Die Anhänger der Reformation wollten Kirche und Gesellschaft mit Hilfe der evangelischen Lehre verändern. Ein Vorhaben, das den entschiedenen Widerstand der Vertreter des alten Systems heraufrief. Es kam zu Unruhen und Aufruhr. Im Frühjahr 1523 schickte der Erzbischof von Riga drei Franziskanermönche, Antonius Bomhover (Bruder des 1518 verstorbenen Bischofs von Dorpat), Augustin Ulfelt und Burkard Waldis, nach Deutschland und Italien, um dort Unterstützung bei Kaiser und Papst zu erwirken ${ }^{27}$. Die Gesandtschaft erhielt vom kaiserlichen Stellvertreter in Deutschland, Markgraf Philipp von Baden, insofern Schützenhilfe, als er die Wiederherstellung der überkommenen Strukturen im Erzstift Riga anordnete und bei Nichtbefolgung der Stadt mit der Reichsacht drohte. Auch sollte der Bann gegen Luther öffentlich vollzogen werden. Dies meldeten die Boten umgehend nach Riga und zogen nach Rom weiter ${ }^{28}$, wo sie bis Ostern 1524 blieben. Über das, was Waldis dort erlebt hat (vgl. Esopus IV 1), läßt sich nur spekulieren. Denkbar ist aber, dass ihn in der Heiligen Stadt Zweifel am Sinn seines Tuns und seiner Glaubensüberzeugung überfallen haben. Auf dem Rückweg sprachen die Franziskaner noch auf dem Reichstag zu Nürnberg vor und baten um Hilfe bei den Glaubenskontroversen. Insgesamt war die Gesandtschaft wohl ein Fehlschlag, es gab kein autoritatives Mandat. Weder Papst Clemens VII. noch Kaiser Karl V. wollten sich im Norden Europas einmischen, denn angesichts der Türkengefahr rückten interne Auseinandersetzungen im Reich auf den zweiten Platz. So beschränkten sich die Anweisungen des päpstlichen Gesandten in Nürnberg, Kardinal Lorenzo Campeggi, auf verbales Strohfeuer. Unterdessen war das Schreiben der Franziskaner nach Riga abgefangen worden und hatte große Empörung beim Rat und in der Bürgerschaft ausgelöst ${ }^{29}$. Es kam zu Angriffen auf den Franziskanerkonvent und Aktionen von Bilderstürmern. Jedenfalls wurden Bomhover und Waldis bei ihrer Rückkehr verhaftet und eingekerkert. Der dritte Mönch hatte sich vorher in Sicherheit gebracht.

Nach sechs Wochen verließ Waldis das Gefängnis als freier Mann. Er trat aus dem Orden aus und bekannte sich zum evangelischen Glauben. Wie ist es zu

${ }^{27}$ Vgl. Отто РонRт, Reformationsgeschichte Livlands. Ein Überblick, Leipzig 1928, 39ff. Über die Romfahrt der Franziskaner schreibt ausführlich LEONID ARBUSOW JR., Des Rigaschen Franziskaners Burkard Waldis Romfahrt und seine nachmalige Rolle während der Reformation Rigas, in: Rigascher Almanach 1914, 107-133; bes.112ff. Vgl. DeRs. (wie Anm. 14), 261ff. - Ganz sicher war Waldis kein unerfahrener und ungebildeter Anfänger im kirchendiplomatischen Geschäft.

${ }^{28}$ Georg Buchenau, Leben und Schriften des Burcard Waldis, Marburg 1858, 9 vermutet eine erste Romreise um 1500. Entsprechend muß er das Geburtsjahr von Waldis früher ansetzen.

${ }^{29}$ Das Schreiben ist abgedruckt bei Lemmens (wie Anm. 4), 61ff., Nr. 281. - Die romfeindliche Stimmung findet deutlichen Ausdruck in einem geflügelten Wort: Wer Bannbriefe ins Land trage, verdiene, in einen Sack gesteckt und unter den Toren der Stadt aufgehängt zu werden (vgl. Arnold E. Berger (Hg.), Die Schaubühne im Dienste der Reformation, Darmstadt 1967, 119). 
dieser Wende gekommen? - Ohne Zweifel muß sie als Ergebnis eines längeren Reflexionsprozesses gewertet werden, der von den Erfahrungen in Deutschland und Italien angestoßen worden war. In manchen seiner späteren Fabeln finden sich Referenzen. So heißt es in der Fabel „Von einer römischen Reise“:
„Einst dachte ich zu werden fromm
und zog aus Deutschland hin nach Rom.
Doch wurd ich auf der Reis nicht bieder,
trug Zwiebeln hin, bracht Knoblauch wieder.
Denn das ist längst ein alte Weis,
wie jeder wohl es selber weiß,
der dort je war, man darfs wohl sagen - :
Zu Rom kriegt man ein bösen Magen,
ein leeres Säckel, bös Gewissen
und wird gar oft ums Geld beschissen.“

Er begegnet einem ehemaligen Studiengenossen und tauscht mit ihm Erlebnisse und Erfahrungen aus. Nachdem das Gespräch auf das sittenlose Verhalten der Kleriker gekommen ist, heißt es in der Fabel mit Sarkasmus:
„Man sagt: Zu Rom kein Sünde schadt, doch wenn einer kein Geld mehr hat, das ist die allergrößte Sünd, die nicht der Papst vergeben künnt ... Drum auch das Sprichwort wahrhaft ist: Je näher Rom, je böser Christ“" (Esopus IV 24) ${ }^{30}$.

Auch die Pracht der Klosterkirche und des Ordenshauses der Franziskaner in Assisi wird mit bitteren Worten beschrieben:
„... daß man sichs wohl verwundern möchte,
wies all durch Betteln zsammen gesucht ...
so ist das Kloster von Asseis
über alle maße und aus der Weis
so köstlich an ein Berg gebaut
daß, wenn mans auch von fern anschaut,

30 Übertragung von Günter E. Th. Bezzenberger, Burkard Waldis. Mönch, Zinngießer, Pfarrer und Dichter, Kassel 1984, 20f. (vgl. KuRz [wie Anm. 3], 75ff.). Diese Fabel läßt nichts an Eindeutigkeit zu wünschen. Die protestantische Perspektive über römische Verhältnisse und Pilgerfahrten nach Rom entfaltet Fabel IV 1 (Vom Wolffe, Fuchß und Esel). Seine Erlebnisse in Nürnberg sind in Esopus IV 17 und 18 verarbeitet (vgl. Buchenau [wie Anm. 28], 11f.). - Diese Wende in Analogie zur Biographie Luthers verstehen zu wollen, liegt verführerisch nahe, ist aber durch keine Informationen gedeckt. CARL SchirRen (Livländische Charaktere. Burchard Waldis, in: Baltische Monatsschrift Bd. 3, Riga 1861, 503-524; 504f.) schlägt eine psychologisierende Deutung vor. 
so wärs einm türkischen Kaiser gnug,

drin zu wohnen nach allem fug ...“(Esopus III 100) ${ }^{31}$.

Im Gewand der Fabel, die spezielles Wissen über die Ereignisse im Franziskanerorden erkennen läßt, wird der Widerspruch zwischen franziskanischem Ideal und weltlicher Realität herausgestellt (vgl. Esopus IV 4). Was als religiöser Anspruch auftritt, ist in Wahrheit Täuschung und fällt unter die dichterische „Entzauberung“632. Mit Hilfe der Fabelfiktion wird die verstellte Wirklichkeit als solche durchschaubar, denn das Ereignis der Reformation stellt durch das Evangelium „Augen der Erkenntnis“ bereit.

4. Waldis blieb in Riga, ergriff einen bürgerlichen Beruf und wurde „kanngeter“/ Zinngießer ${ }^{33}$. Auch diese Phase seiner Biographie läßt vieles im Dunkel. Die „Heftigkeit dieser Wandlung“ „verblüfft“: „,der Mönch wird fast über Nacht Bürger, Ehemann und Handwerker"634. Eine solche Wende vollzieht sich nicht in einem Augenblick, weckt vielmehr Fragen und Spekulationen. Zur Ausübung seines Berufs bedurfte es sicher wichtiger Vorgaben, z.B. des Bürgerrechts und der Aufnahme in die Zunft der Zinngießer. Wer bzw. was hat den sozialen Aufstieg gefördert? - 1526 bewarb Waldis sich um die Meisterrechte und erhielt sie auch. Damals stand gerade die Werkstatt des verstorbenen Kannengießers Matthis Schulte zur Disposition. Ein Rentenkaufbrief aus dem Jahre 1533 nennt den genauen Standort von Werkstatt und Laden, nämlich das Eckhaus an der Schal- und kleinen Neustrasse am Markt ${ }^{35}$. Dort hat Waldis Kannen, Schüsseln, Teller und Pokale angefertigt (s. Abb. 4+5). Auch der Name eines Mitarbeiters wird überliefert: Cyriakus Klinth. 1915 befand sich noch eine Weinkanne aus Waldis' Werkstatt im Museum von Fellin (estn. Viljandi). Johannes Gahlnbäck, ein Metall-Experte im Institut für archäologische Technologie in St. Petersburg, hat sie beschrieben ${ }^{36}$ :

„Die Kanne ist von schlanker Form, der Griff leicht geformt. $304 \mathrm{~mm}$ hoch, ohne Deckel $255 \mathrm{~mm}$. Deckel und Drücker an demselben sind gut gezeichnet (..) Das Stadtzeichen gibt Riga als Herstellungsort an. Das Meisterzeichen daneben zeigt einen in zwei ungleiche Teile geteilten Schild: im grösseren, oberen Teil sieht man die gespreizt dastehende Gestalt eines Mönchleins in der Kutte mit ausgebreiteten

${ }^{31}$ Übertragung von Karl Steinbach/Elisabeth Riegel, Burkard Waldis aus Allendorf an der Werra, in: Das Werraland 39, Heft 1, 1987, 1-3; 1; vgl. KuRz (wie Anm. 3), $417 \mathrm{ff}$.

${ }^{32}$ Vgl. LieB (wie Anm. 3), 129ff.; 136ff.; 142ff.

${ }^{33}$ Das ist die Selbstbezeichnung in der niederdeutschen Vorbemerkung zum Fastnachtsspiel über den Verlorenen Sohn: „Borchart Waldis, kangeter to Riga ynn Lifland, wünscht heyl allen ubnd jedern, den dith böchlin vorkommt“. In der „Anrede“ an den Leser stellt der Autor sich in einem Akrostichon vor. - Vgl. das Glasbild im Dom zu Riga und OJĀRs SpĀritis/ Indrikis Sturmanis, Rigas Doma Vitrazas, Riga 1997, 25ff. - S. Abb. $2+3$.

${ }^{34}$ Mackensen (wie Anm. 2), 61.

${ }^{35}$ Nach einer Urkunde im Rentenbuch des Rigaschen Rates; zitiert bei Buchenau (wie Anm. 28), 14.

${ }^{36}$ Johannes Gahlnbäck, Eine Zinnkanne des Burchard Waldis, in: Mitteilungen aus der livländischen Geschichte Bd. 23, 1924-1926, 578-582; 579. Vgl. DERS., Zinn und Zinngiesser in Liv-, Est- und Kurland, Lübeck 1929. 
Armen, das Haupt mit einem breitrandigen Hut bedeckt; im kleinen unteren Felde ist ein gotisch geformtes W zu sehen“. Alle Details weisen auf eine Werkstatt der ersten Hälfte des 16. Jahrhunderts.

Das Geschäft muß große Zuwächse gehabt haben, denn zum Vertrieb der Waren unternahm Waldis weite Geschäftsreisen nach Amsterdam, Lissabon, Lübeck, Breslau, Naumburg, Mainz und Frankfurt. Diese Städte erwähnt er ausdrücklich in seinen Fabeln (vgl. Esopus IV 13; II 18; IV 4). Reisen, Erfahrungen, Begegnungen mit allen Schichten der Bevölkerung haben in ihm einen Fundus angelegt, aus dem er bei seiner schriftstellerischen Tätigkeit schöpfen konnte; ,seine Kannen brachte er auf die Messen und holte sich Schwänke heim“337. Vielleicht hat er 1535 Luther in Wittenberg getroffen.

5. Am 17. Februar 1527, dem Sonntag Septuagesimae, wurde in Riga sein Fastnachtsspiel „Vom verlorenen Sohn“ (s. Abb. 6) vermutlich in oder vor der Petrikirche aufgeführt ${ }^{38}$. Ein Drama, ,das unkonventionell im Entwurf, geschickt in der Bewältigung des Stoffes und grossartig in der Wirkung war und blieb “39.

$\mathrm{Zu}$ den alten Gebräuchen in der Fastenzeit gehörte es, die religiöse Praxis der Menschen durch Mysterienspiele zu begleiten. Waldis wollte den frivolen Schwänken der Karnevals- und Fastenzeit, die er u.a. aus Rom kannte, eine Alternative, die das Evangelium „schön traktiert“, entgegensetzen. Zu seiner Zeit war die äußere Situation in Riga durch ein erzbischöfliches Interregium und heftige Disputationen zwischen Vertretern des alten Systems (u.a. Antonius Bomhover) und evangelischen Theologen (Andreas Knopken; Nikolaus Ramme ${ }^{40}$ ) geprägt ${ }^{41}$. Darum erscheint das Stück auch als ein Beitrag zur protestantischen Kirchenpolitik. Nicht weniger

${ }^{37}$ SChirRen (wie Anm. 30), 507.

${ }^{38}$ Vgl. Arbusow JR. (wie Anm. 14), 650ff.; Pohrt (wie Anm. 27), 61ff.; 126ff.; Buchenau (wie Anm. 28), 30f. Berger (wie Anm. 29), 131ff.; INGrid SCHröDER, „De parabell Zeitschrift für plattdeutsche Gemeindearbeit, 25. Jhg., Heft 1, 2002, 21-43; 23. - Das Fastnachtsspiel des B. Waldis hat einen berühmten Vorläufer. Im Winter 1204/05 wurde in Riga ein „Prophetenspiel“" aufgeführt. Mit diesem geistlichen Theater wollte Bischof Albert die Anfangsgründe des Glaubens durch Veranschaulichung und Übersetzung verständlich machen „tam neophitis quam paganis“. Vgl. LuTZ MaCKEnsEn, Das „Rigaer" Prophetenspiel von 1205, in: Zur deutschen Literatur Altlivlands, Ostdeutsche Beiträge aus dem Göttinger Arbeitskreis Bd. 18, Würzburg 1961, 10-20; REINHARD SCHNEIDER, Straßentheater im Missinseinsatz. Zu Heinrichs von Lettland Bericht über ein großes Spiel in Riga 1205, in: Manfred Hellmann (Hg.), Studien über die Anfänge der Mission in Livland, Sigmaringen 1989, 107-121.

${ }^{39}$ Mackensen (wie Anm. 2), 63. Vgl. Pols Medžviks (ed.), Burkard Waldis - Parabola par pazudušo dēlu, Riga 2010 mit Beiträgen von Dieter Andresen und Ilze ŠarkovskaLiepina.

${ }^{40}$ Nikolaus Ramme stammte aus Riga, hatte in Rostock studiert und sich früh der Reformation angeschlossen. Er gehörte neben Lorenz von Scheden zu den Predigern für die Evangelischen lettischer Sprache.

${ }^{41}$ Die Zusammenhänge schildert Arbusow JR. (wie Anm. 14), 646ff.; vgl. auch TheOdor Schiemann, Antonius Bomhower und Andreas Knopken. Eine Episode aus der Reformationsgeschichte Rigas, in: Baltische Monatsschrift Bd. 32, Riga 1890, 351-360; Ferdinand Hoerschelmann, Andreas Knopken - der Reformator Rigas, Leipzig 1896. 
als fünfmal gibt der Dichter der Grundthese Luthers, dass der Christ allein durch Glauben und ohne Zutun der Werke gerecht werde, Raum: „Aus rechter Gnad und eitel Gunst/ ohn all unser Zutun, Werk und Kunst“" (V. 85f., V. 183f., V. 1087f., V. 1564f., V. 1824f.). Waldis ,popularisiert in dramatischer Form, was Luther in seinem Schreiben formulierte“442. Ohne den Namen seines früheren Weggefährten Bomhover zu nennen, richtete sich die Polemik des Stücks gegen ihn und die römische Institution (vgl. auch V. 111-114; 125-132). Jedermann wußte, wer der mit dem ,unreinen Mund“ gemeint war:

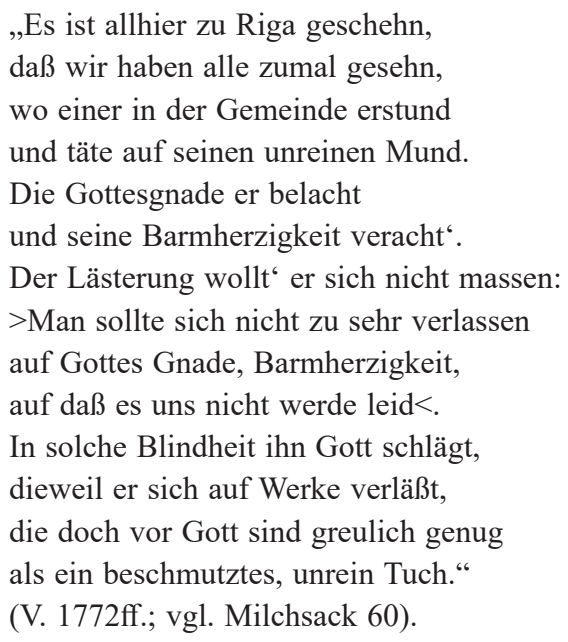

Solchen Lästerern sollte der „Mund gestopft“ (vgl. V. 188ff.) werden. Mit Polemik und Satire gelang es Waldis, die reformatorische Glaubensüberzeugung (Allein die Gnade rechtfertigt.) hermeneutisch adäquat (sola scriptura) und volksnah (in niederdeutscher Sprache) zu entfalten. Bei der dramaturgischen Präsentation und sprachlichen Verarbeitung des Jesusgleichnisses aus Lukas 15,11-32 war damit zu rechnen, dass die Zeitgenossen Vorkenntnisse mitbrachten. Denn die Parabel hatte schon immer Prediger und Künstler angeregt. Vielleicht kannte Waldis die vierzig Fastenpredigten des Baseler Franziskaners Johannes Meder über den Text $^{43}$. Der biblische Stoff wird getreulich nacherzählt und für den aktuellen Augenblick instrumentalisiert. An einer Stelle weicht Waldis von seinem Referenztext ab. Der ältere Sohn reklamiert zwar seine Ansprüche (V. 28ff.). Er meint aber, den Fundus seiner guten Werke vergrößern zu müssen und beschließt, Mönch zu werden (vgl. V. 1481ff.). Beim Aufbau des Stücks - erstmalig in der deutschen Literatur wird die Einteilung eines Dramas in Akte vorgenommen orientierte sich Waldis am Ablauf des Gottesdienstes. Der Text präsentiert sich „in seiner Komposition“ wie „das Protokoll einer reich ausgebreiteten Liturgie“

${ }^{42}$ SCHRÖDER (wie Anm. 38), 37.

${ }^{43}$ So Mackensen (wie Anm. 2), 67ff. Vgl. Berger (wie Anm. 29), 142: „Die ProdigusParabel gehört zu den Lieblingsstoffen des erziehungsseligen 16. Jahrhunderts“. 
(W.Brettschneider). Aus dem Publikum bildet sich eine Gemeinde, wenn die Menschen die eingefügten Lutherchoräle, die in der Stadt wohlbekannt sind, mitsingen. Am Anfang des Dramas steht ein Gebet. Dann folgt die Verlesung des Evangeliums, vorgetragen von einem Kind. Ein „Actor“ (Spielleiter/Regisseur) begleitet den Ablauf der Handlung mit Deutungen, die in predigtartige Passagen übergehen und mit typologischen Reflexionen auf die Applikation der Botschaft des Textes zielen. Seine Beiträge machen fast die Hälfte des Stückes aus. Am Schluß des ersten Aktes, der den Sohn im tiefsten Elend zeigt, wird eine Umdichtung des 13. Psalms gesungen (vgl. V. 1277). Zum Ende des zweiten Aktes, vor dem Fest, ertönt das Lied „Aus tiefer Not“ (vgl. V. 1934), nachdem der Schurkenwirt aus dem ersten Akt seine Sünden bekannt und der Actor noch einmal das reformatorische Leitmotiv (V. 1864-1869) in Erinnerung gerufen hat. Auf dem Höhepunkt der Darbietung, nachdem die Heimkehr des Verlorenen Sohnes vollzogen ist ${ }^{44}$, singen die Zuschauer das hussitische Abendmahlslied „Jesus Christus unser Heiland“ (vgl. V. 1375). Am Ende zieht der Actor Bilanz und richtet sich an die Zuschauer:

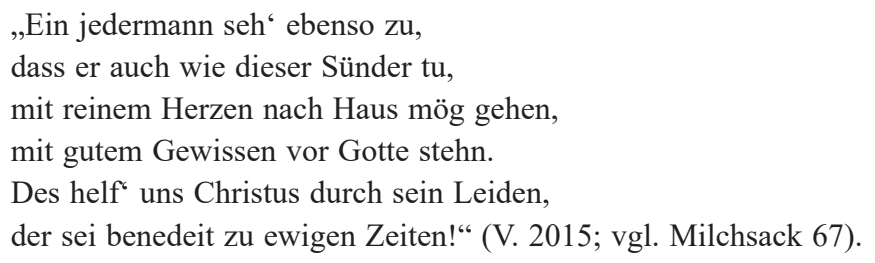

Das letzte Wort ist der aaronitische Segen, die „,benedyunge“, wiederum erteilt von einem Kind. Mit seinem Stück greift Waldis in das aktuelle Zeitgeschehen ein und mutet den Zuschauern zu, eine religiöse Entscheidung mit politischer Tragweite zu treffen.

Ob Waldis vor dem „Verlorenen Sohn“ schriftstellerisch tätig war, ist nicht belegt. Sein Stück weist ihn jedenfalls als einen Dichter aus, der volksnahe Rhetorik (niederdeutsche Sprache), Sensibilität für den Kontext (Rigaer Kolorit; Schlemmerlied in der Zechszene (V. 703ff.): „Wo soll ich mich ernähren, ich armes Brüderlein“; Spruchgut) und theologische Bildung (altkirchliche Exegese und lutherische Theologie) genial miteinander verbinden konnte. ,Seine Sprache ist ein markiges, herbes und schlichtes Niederdeutsch mit mancherlei hochdeutschen Einschlägen, die teils seiner niederhessischen Heimat angehören, teils auch literarischer Herkunft sind. Seine vierhebigen Verse mit oft frei behandelten Senkungen lassen den gefälligen Einklang von Satzton und Verston selten vermissen, sie machen nirgends den Eindruck mühsamen Flickwerks, sondern einer ungezwungen sich ergießenden natürlichen Beredsamkeit ${ }^{645}$. Zwar entschuldigt er sich bei seinem Publikum für die populäre

\footnotetext{
${ }^{44}$ Die Festszene nach der Heimkehr des verlorenen Sohnes wird auf das Abendmahl hin interpretiert; vgl. V.1700ff.: „Dat gemeste kalff nu CHRISTUS ys, / De wert geslacht und geten gewyss" (vgl. Milchsack 58ff.).

${ }^{45}$ Berger (wie Anm. 29), 142.
} 
Präsentation - „Dass unser Stilus ist so schlicht,/mit Terentio gar wenig stimmt,/noch mit Plauto übereinkümmt“ (V. 212ff.) - doch ist sein „Verlorener Sohn“ das erste Drama in deutscher Sprache, das die antiken Gesetze des Theaters aufgreift ${ }^{46}$.

Ohne Zweifel hat Waldis mit seinem Werk die Position der evangelischen Seite gestärkt, sich als glaubwürdigen Vertreter lutherischen Denkens eingeführt und hohes Ansehen in der Stadt ${ }^{47}$ gewonnen. U.a. wurde er 1530 zum Geschäftsträger des Rates der Stadt beim Reichskammergericht in Speyer bestellt. Verschiedentlich holte man bei Finanzfragen sein kaufmännisches Urteil ein. Sowohl für den Ordensmeister wie für den Rat hat er Münzgutachten erstellt ${ }^{48}$. Ebenso war er beteiligt an der Ausarbeitung der Rigaer Kirchenordnung. In der zweiten Auflage von 1537, die ein Gesangbuch einschließt, hat er ,Ein gebedt zu Gott ${ }^{649}$ beigesteuert. Von ihm stammt auch der gereimte Text zum Eingang:

„Geistlich sanckbuechlen man mich nent,

$\mathrm{Zu}$ Riga in Lyfflandt wol kent,

Da selb byn ich Christlicher gemein,

Zu dienst wan sy syngen yn eynn

Und sunderlich der lieben Jugent,

Dye sich vleyst Christlicher tugent,

Vill neyer Psalmen und geseng,

Auch mit den Noten ich hie breng,

Mit wortten und orsachen,

Woruym man mich thet ney machen

${ }^{46}$ Das Fastnachtsspiel wurde noch 1527 in Rostock gedruckt. Das einzig erhaltene Exemplar liegt in der Wolfenbütteler Bibliothek; ein Nachdruck wurde 1881 von GuSTAV MilchSACK (= Neudrucke deutscher Literaturwerke Nr. 30) besorgt. Dem Druck sind sechs Kirchenlieder in niederdeutscher Sprache beigegeben, drei von Waldis selbst und drei von Andreas Knopken (Texte bei Johannes GeFFCKen (Hg.), Kirchendienstordnung und Gesangbuch der Stadt Riga. Nach den ältesten Ausgaben von 1530, Hannover 1862, XVIII; 103ff.; 106f.; 108ff.). - Dass die neuere Literaturwissenschaft sich mit Burkard Waldis beschäftigt, zeigt neben Ludger Lieb (vgl. Anm. 3) auch Volkhard Wels, Versuch einer dialektischen Analyse von Burkhard Waldis Parabel vom verlorenen Sohn (1527), in: Alexander Schwarz/Laure Abplanalp (Hg.), Text im Kontext. Anleitung zur Lektüre deutscher Texte der frühen Neuzeit, Frankfurt/Main u.a. 1997, 301-317.

${ }^{47}$ LutZ Mackensen (Gedanken über die Rigaer Zeit des Burkard Waldis, in: Zeitschrift für Volkskunde 46, 1936/37, 91-100) versucht das Dunkel über der Rigaer Zeit aufzuklären und kommt zu dem (hypothetischen) Ergebnis, dass Waldis in Riga die „Laufbahn eines geheimen Politikers" eingeschlagen hatte. Der bürgerliche Beruf sei Tarnung gewesen und mit städtischer Protektion erfolgt. Mit Geschäftsreisen habe Waldis seine politische Mission als Unterhändler und Agent verschleiert. Mackensen sieht ihn als „Politiker“ und schließlich „Verschwörer“. Was sein literarisches Wirken angeht, so sei er „mehr Werkzeug als selbstschöpferischer Geist" gewesen. Andreas Knopken habe ihn zur Abfassung des Fastnachtsspiels angeregt, um die eigene theologische Disputation mit Bomhover zu popularisieren. - Anhalt an den vorhandenen Quellen haben diese Mutmaßungen kaum, auch wenn Einzelheiten Möglichkeitswert haben.

${ }^{48}$ Vgl. Buchenau (wie Anm. 28), 16; 31. Der Titel der Denkschrift lautet: „Ene underrichtinghe, women best solde moghen kamen jn Lyfflande to gudem golde to macken, dat bestendich were" (zit. bei MichSACK [wie Anm. 3], 18).

${ }^{49}$ Text bei GefFcken (wie Anm. 46) 150f. 
Der halben geliebter leser sich,

Um eyn kleyn gelt kauffstu mich,

Und ich dyr gros nutzen kan,

Wie du wirst lesende wol vorstan“".50

6. Trotz dieser Erfolge war die Rigaer Zeit von unglücklichen Ereignissen überschattet. Seine Ehe mit der Witwe Barbara Schulthe aus Königsberg, deren Schulden er bei der Heirat bezahlt hatte, zerbrach, wozu sicher beide Seiten ihren Teil beigetragen haben. „Von den Flitterwochen ist nichts überliefert, um so mehr von den Bitterwochen. Er liebte den Wein und sie das Bier" ${ }^{651}$. Nachdem er seine Frau aus dem Haus vertrieben hatte, schwärzte sie ihn beim Ordensmeister an. Wahrscheinlich hat diese Episode zu bissigen Ausfällen gegen die „bösen Weiber“ geführt, von denen in manchen seiner Fabeln zu lesen ist.

„Es ist, glaub mir, zu aller Frist

kein größer Leid, daß einer ist

mit einem bösen Weib beladen.

Sie können einen in Leid und Schaden

Bringen mit Lüge und bösem Schwätzen, damit sie die Leut zusammenhetzen.

Es sollte einer lieber Steine tragen

Auf die Mauer und alle Arbeit wagen, denn daß einer seine Zeit vertreibt in Leid mit einem bösen Weib, und viel lieber des Todes sterben, denn solch einen zähen Balg zu gerben, und lieber der Welt Unglück haben, denn solch ungeschmeidig Leder schaben. Man sagt, wer blind sei, der sei arm, ist billig, daß man sich seiner erbarm.

${ }^{50}$ Zit. bei GeFFCKEN (wie Anm. 46), 146. Es folgt noch ein Vorwort an die Leserschaft (vgl. 147-149).

${ }^{51}$ SCHIRren (wie Anm. 29), 508. In einem Brief an die Schwägerin Christina von 1531 beklagte er sich über die Schlechtigkeit und Undankbarkeit der Ehefrau (zit. bei Schirren 509 und Milchsack [wie Anm. 3], 21-23). - Legendenhaft überzeichnet sind die Nachrichten, Waldis habe seine Frau verhext, nachdem diese das gemeinsame Haus verlassen habe, um zurück nach Königsberg zu gehen. Es heißt, er habe sie verflucht: „sie solle nur mit dem Schiffe, Schiffer und anderen Kaufgesellen von hinnen ziehen, sie sollten noch sämtlich die Füße in der See waschen“. Trotz günstigen Wetters sei das Schiff nicht vorwärts gekommen. Erst nachdem die Besatzung Gegenzauber eingesetzt habe, sei das Ziel wie im Augenblick erreicht gewesen. Waldis' Ruf in der Stadt habe unter diesen Vorkommnissen gelitten; vgl. Christoph Schmidt, Auf Felsen gesät. Die Reformation in Polen und Livland, Göttingen 2000, 248. 
Doch ist der ein viel ärmerer Mann,

welcher sein Weib nicht zwingen kann“ (Esopus IV 67) ${ }^{52}$.

Die Probleme eskalierten unter dem erzbischöflichen Koadjutor Markgraf Wilhelm von Brandenburg, als die politischen Pläne des Stadtsyndikus Lohmüller, das Erzbistum nach dem Vorbild Preußens in ein weltliches Herzogtum umzuwandeln ${ }^{53}$ und so die Reformation zu sichern, an die Öffentlichkeit drangen. Der Politiker Lohmüller mußte sich nach Königsberg absetzen, verfolgte aber von dort aus seine politischen Pläne weiter. Waldis, der mit ihm befreundet war, verrichtete „Botengänge“ zwischen Königsberg und den übrigen Verschwörern. Als Waldis im Herbst 1536 in Bauske angeheiratete Verwandte besuchen wollte, ließ ihn der Ordensmeister Hermann von Brüggeney unter der Anklage ketzerischer Umtriebe, Verschwörung und Aufruhr gegen den Deutschen Orden verhaften. Während der Gefangenschaft war er brutaler Folter ausgesetzt, um Informationen zu verraten ${ }^{54}$. Die Haft in Bauske/lett. Bauska, Wenden/lett. Cēsis und Fellin/estn. Viljandi hat ihn in Todesnähe und große seelische Bedrängnis gebracht (vgl. Esopus IV 78). In dieser Zeit begann er, Psalmen in volkstümliche Sprache zu übersetzen und Kirchenlieder zu dichten, ganz sicher seine Art, die Umstände der Haft zu verarbeiten.

\author{
Psalm 25 \\ „An allen Menschen gar verzagt \\ $\mathrm{Zu}$ dir mein Seel will geben, \\ Herr Gott, auf dich hab ichs gewagt \\ Erhalt mich bei dem Leben. \\ All mein Zuflucht stell ich an dich, \\ laß nicht zuschanden werden mich, \\ daß sich mein Feind nicht freuen. \\ Mein Augen sind allzeit zu dir, \\ o Herr mein Gott, gerichtet, \\ daß du helfst aus dem Netze mir, \\ dern, die mich han vernichtet. \\ Erbarm dich mein und sieh mich an,
}

52 Übertragung von Steinbach/Riegel (wie Anm. 31), 3; vgl. Kurz (wie Anm. 3), 162ff. Bittere Erfahrungen stehen auch hinter Esopus IV 19, 123ff.; vgl. KuRz (wie Anm. 3), 55ff. und MilchSACK (wie Anm. 3), 23; 29.

${ }^{53}$ Über die „Verschwörung“ und ihre Vorgeschichte seit 1532 schreibt ScHIRREN (wie Anm. 29), $515 \mathrm{ff}$.

${ }^{54}$ Davon handelt ein verschlüsseltes Schreiben von Anfang Januar 1537 des Ordensmeisters an den Ordensvogt zu Bauske; zitiert SchirRen (wie Anm. 29), 519f. - Nach SCHIRREN sind die leidvollen Episoden in Riga das Resultat der Mischung „Mönchsklugheit und zünftischer Engherzigkeit" (513). Dagegen sieht ArBusow in Waldis' politischen Aktivitäten naive Selbstüberschätzung am Werk. „Seine Rolle in der Reformation Rigas war ausgespielt, als er sich über die Grenzen hinauswagte [..] als er unternahm, nicht bloß die Seelen und Gedanken zu beeinflussen, sondern in den harten Gang der großen Dinge der Welt selbst einzugreifen" (wie Anm. 14), 133. 
denn arm bin ich, von jedermann

auch gar und ganz verlassen.

Meins Herzen weh richt mich jetzt hin, komm, Herr, und tröst mich wieder, schau, wie ich gar vernichtet bin, im Elend lieg danieder, darum vergib die Sünde mein, sieh an, wie viel der feinde sein, die mich ohn Grund verfolgen“.

\section{Psalm 121}

„Wenn ich in Angst und Nöten bin und all mein Trost ist gar dahin, so heb ich auf meine Augen hoch zum Herrn um Hilf und denk ihm nach und wart bis mir geholfen wird von Gott des Himmels und der Erd.

Er hält mich auf der rechten Bahn Und wird mein Fuß nicht gleiten lan. Der Herr ist's, der mich selbst behüt, obgleich der Feind trotzt, tobt und wüt ...

Zum Schutz ist stets der Herr bereit Vor allem Übel allezeit, den Trost verzieht er nicht zu lang, behüt dein Ausgang und Eingang, hilft dir zuletzt aus allem Leid von nun an bis in Ewigkeit"55.

Unterdessen hatte seine Familie in Hessen über seinen Zustand Nachricht erhalten. Seine Brüder kamen 1538 nach Riga und erwirkten Hafterleichterung sowie die Zusage eines gerechten Prozesses. Als aber auch das vermittelnde Eintreten des hessischen Landgrafen Philipp (1540) keinen Fortgang des Verfahrens erreichte, kamen die Brüder eine weiteres Mal nach Riga und wurden zusammen mit dem Rat der Stadt und kräftiger Fürsprache des hessischen Landgrafen beim Ordensmeister vorstellig. Sie hatten Erfolg. Nach dreieinhalbjähriger Kerkerhaft wurde Waldis am 21. Juli 1540 entlassen. Am selben Tag erfolgten auch die besitzrechtliche Einigung

55 Übertragung von Bezzenberger (wie Anm. 30), 88 und 98f. - Der 25. Psalm liegt auch in einer niederdeutschen Fassung von Andreas Knopcken vor. Der Psalm findet sich in der Druckfassung von Waldis' Theaterstück und ist in die Rigaer Kirchenordnung von 1537 aufgenommen worden (vgl. GeFFCKen [wie Anm. 46], 103ff.). Die hochdeutsche Übersetzung von Waldis muß als eigenständige Version betrachtet werden. 
mit seiner Frau und die Scheidung. In Riga fühlte Waldis sich nicht mehr sicher. Auch sah er geschäftlich für sich keine Zukunft. Daher übertrug er die Zinngießerei seinem früheren Mitarbeiter Cyriakus Klinth. Seine Gesundheit hatte während der Gefangenschaft Schaden gelitten, aber er hatte noch sein Leben. Nach der Freilassung schrieb er in einem Lied:

\section{„Gott lob, dass uns jetzt wird verkündt die Evangelisch Lehre. \\ Himmel und Erd mit vollem Mund \\ Erzählen Gottes Ehre“"56.}

7. Er kehrte in seine hessische Heimat zurück. Nachdem seine Gesundheit wieder hergestellt war, beschloß er Theologie zu studieren. Zunächst ist er in Marburg und im Winter 1541 als „Burchardus Vualdis Hessus“ an der Universität Wittenberg unter Rektor Jacobo Milichio immatrikuliert (Matrikel Wittenberg I, 192, Nr. 23). Hat er evtl. Vorlesungen bei Luther und Melanchthon gehört? An die Studienzeit schloß eine längere Wartephase an, in der Waldis seine literarische Tätigkeit wieder aufnahm und vertiefte. Während des Schmalkaldischen Krieges (1546-1547) unterstützte er den hessischen Landgrafen Philipp mit literarischen Werken. So griff er in die Auseinandersetzung mit Herzog Heinrich von Braunschweig-Wolfenbüttel ein und betätigte sich als ,politischer Dichter ${ }^{657}$. Gegen diesen unangenehmen Zeitgenossen und erbitterten Gegner der Reformation veröffentlichte er 1542 drei derbe Pamphlete. Im Jahr darauf folgten drei satirische Streitgedichte gegen die katholische Geistlichkeit: „Ein warhafftige Historien von Zweyen Mewssen. So die pfaffen im Hüttenberge bey Wetzalar haben verbrennen lassen. Darumb das sie ein Monstrantzen Sacrament gefressen haben“. Dann erschien noch ein mit Reimen versehenes Bilderbuch über die alten Könige der deutschen Nation.

1543/44 wird Waldis urkundlich als zweiter Pfarrer an der Altstädter Kirche in Hofgeismar erwähnt ${ }^{58}$. Er verwaltete wohl schon seit 1542 die Stelle nach dem Tod von Pfarrer Dr. Johannes Westermann ${ }^{59}$, dessen Witwe er schließlich heiratete. Dem

${ }^{56}$ Zit. bei Huck (wie Anm. 26), 83. Das Manuskript befindet sich in der Universitätsbibliothek Kassel, Murhard Bibliothek, Handschrift $4^{\circ}$ Ms.mus. 94, 1, Nr. 20.

${ }^{57}$ Buchenau (wie Anm. 28), 19; 32f.: „Der Wilde Man von Wolfenbuttel“; „Hertzog, Heinrichs vonn Braunschweig Klage Lied“; „Wie der Lycaon von Wolffenbuttel, jcz newlich in einen Münch verwandelt ist".

${ }^{58}$ Zur Episode in Hofgeismar vgl. Helmut Burmeister, „Gottes rechte Hand kann alles ändern“. Leben und Wirken des zeitweiligen Hofgeismarer Pfarrers Burkard Waldis, in: Zeitschrift des Vereins für Hessische Geschichte 99, 1994, 87-100; 90ff. Auf der Gedenktafel in der Altstädter Kirche Hofgeismars, die an alle Pfarrer erinnert, findet sich auch der Name Burkard Waldis.

${ }^{59}$ Westermann stammte aus Münster. Nach geistlichen Studien im Wittenberger Augustinerkloster, wo er Luthers Bekanntschaft gemacht hatte, war er nach Westfalen (Lippstadt) zurückgekehrt. Dort verließ er bald der Orden, trat zum evangelischen Glauben über und wirkte im Geiste Luthers schließlich auch in Hofgeismar, wo der hessische Landgraf ihm eine Pfarrei verlieh. Während einer Reise nach Lemgo, wo er im Auftrag des Landgrafen einen Streit schlichten sollte, erkrankte er und verstarb bald. Zu Westermann vgl. JocheN 
Paar wurden mehrere Kinder geboren. Aber auch diese Ehe scheint nicht besonders glücklich gewesen zu sein.

Im Herbst 1544 war Burkard Waldis endlich am Ziel seiner Wünsche. Der hessische Landgraf übertrug ihm die renommierte Pfarrei Abterode ${ }^{60}$ (s. Abb. 9), wo er der erste evangelische Pfarrer war. $\mathrm{Zu}$ dieser Regelung hatte beigetragen, dass der letzte fuldische Propst, Rudolf Schenk zu Schweinsberg, dem Landgrafen die Besetzungsrechte in Abterode übertragen hatte. So wurde Burkard Waldis evangelischer Propst und Pfarrer in einer Person. Mit Eifer und großem Ernst ging er seinen pfarramtlichen Aufgaben nach, mußte aber mit Rücksicht auf seine Gesundheit auswärtige Verpflichtungen (u.a. Gottesdienste in der Neustädter Kirche in Eschwege und auf dem Cyriakusberg) ablösen. Im gemeindlichen Zinsregister jener Jahre ist Waldis mit Einträgen und Unterschrift vertreten ${ }^{61}$.

War Waldis bereits zuvor als Schriftsteller hervorgetreten, so brach in Abterode für ihn eine äußerst produktive Zeit an. 1548 erschien in Frankfurt sein wichtigstes Werk, der „Esopus. Gantz New gemacht und in Reimen gefaßt. Mit samt Hundert Newer Fabeln" ${ }^{" 62}$ (s. Abb. 7). In vier Büchern mit über vierhundert Beispielen verarbeitet Waldis alle damals bekannten Fabeln im Anschluß an die klassische Quelle. Im vierten Buch stellt er eigene Fabeln vor. Das Werk ist dem Rigaer Bürgermeister Johann Butte gewidmet. Es zeigt Waldis als einen belesenen Menschen (Ovid, Horaz u.a.), der die Fabeln nicht nur übersetzte, sondern in humorvoller und satirischer Weise pädagogische Tendenzen in die Texte eintrug, Nutzanwendungen für das Leben. Mit ausgeprägter Beobachtungsgabe, Kenntnis der Volksliteratur, der Sprichwörter und Redensarten erreicht er ein Niveau von Aktualität und Anschaulichkeit. In stilistischer Hinsicht bevorzugt er unregelmäßige Knittelverse mit vier Hebungen. Außerdem trifft man immer wieder Anspielungen auf die livländischen Verhältnisse bzw. kritische Seitenhiebe auf Zustände in der römischen Kirche.

\footnotetext{
Von der Beichte eines Gesellen

„Vor Zeiten, da die Mönch und Pfaffen

Gewalt hatten, die Laien zu strafen, besonders wenn sie kamen zur Beicht in der Karwoche, so geschah es leicht, daß sie die hart strafen wollten,
}

Desel, Pfarrergeschichte des Kirchenkreises Hofgeismar von den Anfängen bis 1980, Marburg 2004, 390f.

${ }^{60} \mathrm{Im}$ Jahre 1077 gründete Abt Ruthard von Fulda hier eine dem Bonifatius geweihte Propstei. Zwistigkeiten mit dem benachbarten Kloster Germerode führten zu Bedeutungsverlust. Im 15. Jahrhundert ging die Propstei ganz ein.

${ }^{61}$ Die Akten liegen im Archiv der Evangelischen Kirche von Kurhessen-Waldeck/Kassel.

${ }^{62} \mathrm{Vgl}$. Arbusow JR. (wie Anm. 14), 657f; Buchenau (wie Anm. 28), 33f.; Lieb (wie Anm. 3). - Waldis berichtet von Reiseerlebnissen, Merkwürdigkeiten und abstrusen Dingen. Man sollte die Verbindung zu seiner Biographie nicht zu rasch herstellen, sondern nach der literarischen Funktion fragen. Das damalige Rom z.B. trug in der öffentlichen Meinung das Etikett „Sündenbabel“ wie später andere Städte in Europa. 
denen sie ein Jahr lang grollten; wodurch sie dann die armen Gewissen nicht bauten sondern mehr zerrissen. Wenn man sie aber mit Gaben bestach, so ließen sie von der Buß etwas nach. War einer gegen sie wohltätig, dann war auch unser Herrgott gnädig. Da kenn ich einen jungen Gesellen, der wollte sich einst frömmelnd stellen, kam zu einem Mönch, der kannt ihn wohl, bedachte, wie ers anstellen soll: „Bring ich ihm nicht ein gut Präsent, so spricht er mir ein bös Sentenz, und was ich beicht, wird mir zum Ärger." Nahm in die Hand zwei Schreckenberger Und rieb die Münzen; der Mönch sie sah Und ihm darauf den Ablaß sprach Und löste ihn von aller Sünd.

Als nun der Gesell wieder aufstund Einen Kreuzer warf er ihm nur hin, da merkt der Mönch erst seinen Sinn und sprach, da er den Kreuzer aufhub: „Du bist ein Bub und bleibst ein Bub!“ So geht's, wenn man das Wort Gotts frei verkauft und machts zur Krämerei.

Versündigen sich beid: der es kauft Und der mit ihm auf den Jahrmarkt lauft. So ist die göttlich Schrift verkommen Und Geiz hat Überhand genommen. Ich glaub, wär's länger so geblieben Und hätt der Luther nicht geschrieben, wärn wir ärger worden denn die Heiden und Gott würd ewiglich uns meiden“63.

Die Fabeln des „Esopus“ haben neben dem o.g. Fastnachtsspiel Burkard Waldis einen festen Platz in der deutschen Literaturgeschichte zugeteilt.

Flugschriften und Bilderbögen waren in der frühen Neuzeit die Kommunikationsmittel, um über besondere Ereignisse zu informieren. So hat Waldis 1551 über einen Kriminalfall berichtet: „Ein warhaftige und ganz erschreckliche Historien, wie ein Weyb ire vier Kinder tyrannigklich ermördert und sich selbst auch umbbracht hat. Geschehen zu Weydenhausen bey Eschweh in Hessen“. Der Bericht wurde mehrfach nachgedruckt. Ein anderer Fall betrifft ein monströses Ereignis, das

${ }^{63}$ Übertragung von Bezzenberger (wie Anm. 30), 80f.; vgl. Kurz (wie Anm. 3), 95f. 
Waldis in einem bänkelsängerischen Spruchgedicht thematisierte: „Eine wunderliche Geburt eines zweiköpfigen Kindes zu Witzenhausen in Hessen geschehen, den dritten Tag nach Trium Regum anno 1542“64. Der Dichter verstand sich auf die Kommunikationsformen der Zeit. Zugleich nutzte er die kommunikative Plattform als lutherischer Prediger:
„Weils aber nicht mit unserm Tun
Wird ausgerichtet, daß wir zur Sühn
Keins Wegs kommen mögen vor Gott,
Laßt suchen den, welchen er hat
Zum Mittler gesetzt, den Herren Christ,
Bei dem all Gnad und Seligkeit ist,
$\mathrm{Da}$ er uns beim Vater vertret,
So wird angenehm sein unser Gebet.
Denn all Zusag und Gottes Gaben
Durch ihn allein ihr Wirkung haben
In dem, der's nimmt im Glauben an,
Das soll gesagt sein jedermann" 65 .

Mit den „Psalmen“ hatte Waldis sich in mehreren Phasen beschäftigt ${ }^{66}$. Bereits die Druckausgabe seiner Dramatisierung des Gleichnisses vom Verlorenen Sohn enthielt eine Übersetzung des 127. Psalms. Dieser Psalm stand bekanntlich im Mittelpunkt des Briefes, den Martin Luther 1524 an die Christen in Riga geschrieben hatte (vgl. WA 15, 348ff.). In Verbindung mit seinem früheren Schreiben (1523), in dem die Rechtfertigung sola fide (Röm 3, 28) Thema war, hat Luther einen wesentlichen Impuls gegeben. Das zeigt u.a. die dritte Strophe bei Waldis, in der es (abweichend zum Psalmtext) heißt:
„Darumm merckt up und seht nu ann,
Degy ane glouen leuenn.
Iw brodt soken mit vor up stann,
He willt alßo nicht geuenn.
De ohn früchten den velt ydt tho,
Imm slaep ane alle noth und möyg,
De syner gnad vorwachtenn" ${ }^{“ 67}$.

${ }^{64} \mathrm{Zu}$ diesen beiden Schriften vgl. GüNTHER FranZ, in: Das Werraland 5, 1953, 25f. Zwei Exemplare dieser Flugschriften befinden sich in der Zentralbibliothek in Zürich.

${ }^{65}$ So der Schluß in dem Bilderbogen „Eine wunderliche Geburt ...“; zit. bei Franz (wie Anm. 64), 26.

${ }^{66} \mathrm{Zu}$ diesem Komplex vgl. Max HoRn, Der Psalter des Burkard Waldis. Ein Beitrag zur Geschichte des deutschen Kirchenliedes im XVI. Jahrhundert, Diss. Halle 1911 sowie den Beitrag von Ilze Šarkovska-Liepiņa in: Pols Medžviks (ed.) (wie Anm. 39), $172-189$.

${ }^{67}$ Zit bei Horn (wie Anm. 66), 26. 
Während seiner Haft muß Waldis intensiv den Psalter gelesen und übertragen haben, um „die langweilige(n) unnd beschwerliche(n) gedanken, und Teuffeliche anfechtung damit zuuertreiben“. In der Vorrede zum Gesamttext hebt er den seelsorglichen Charakter des Psalters hervor: „Dann die Psalmen gemeynlich der art und natur sind, daß sie dem menschen im glück und unglück das hertz, und die affekten rüren, und wie dieselbigen gestelt und gethan sein, wie in einem spiegel anzeygen und dargeben, wie solchs alles wol wissen, alle die in fährlichkeyt gesteckt, und die psalmen in nöten und anfechtungen gebraucht haben" "68. Weitere Übersetzungen sind entstanden, nachdem er die Freiheit wieder erlangt hatte. Jetzt konnte er auch seine Arbeit abschließen und drucken lassen. Das Werk erschien 1553 (s. Abb. 8). Es ist seinen Brüdern Hans und Bernhard, die ihm in schwerer Zeit beigestanden hatten, gewidmet. Das Buch enthält 155 Lieder. Jeder der 150 Psalmen ist zu einem Lied umgedichtet worden. Von den Psalmen 13, 20, 138, 142 und 143 liegen je zwei Übertragungen vor.

Vergleicht man Bibeltext und Psalmlieder miteinander, läßt sich eine Einteilung in zwei Textgruppen vornehmen, die sich gattungsmäßig unterscheiden lassen. Einmal sind es Lieder, die streng dem Bibeltext folgen und ,nur eine versifizierte Prosa“ darstellen. Dann sind es Lieder, die „lediglich den Gedankengang“"69 mit dem Psalmtext teilen und ansonsten selbständig formuliert sind.

\section{Psalm 23}

„Gleich wie ein Schaff, im holtz verwirt

Und gar verirt,

Wanns nit der Hirt

Bald innen wirt

Und ruffts $\mathrm{zu}$ jm

Mit seiner stimm,

so frißts gewiß der wolff so grimm:

Also sind wir auch alle sand
In Gottes hand:
Er ist der hirt,
uns furen wirt
Auff gruner aw,
in kulem thaw,
daß uns die gute weyd erfraw.

Der HERR erquickt mein seele baß,

auff rechter straß

Gar sicher furt,

da mich nit rurt

Kein boß gefehr:

${ }^{68}$ Zit bei Horn (wie Anm. 66), 24.

${ }^{69}$ Horn (wie Anm. 66), 35. 
Das selb thut Er

Alls umb seins heilgen Namens ehr.

Wann ich schon wandert uberal

Im finstern thatl,

Furcht ich doch kein

ungluck noch pein,

So stelt Er sich

Gegn mich freundtlich,

sein steck und stab, die trosten mich.

Hat mir gegn alle fehrligkeyt

Einn tisch bereyt,

Mein haupt begeußt

Mit öl das fleußt,

All unfäll lenckt,

meinr stedts gedenckt

und meinen becher vol einschenckt.

Sein gnad, gut und barmhertzigkeit

Volgt mir all zeit

Mein leben lang,

daß ich jm danck,

Er hilfft mir gar

Auß aller fahr:

Beim HERREN bleib ich immerdar.

Lob sei dem Vatter in seim thron

Und seinem Son,

Der uns vom todt

Erretet hat,

Dem Heilgen geyst,

der uns geleyst

sein gnad und hülff allzeit beweist." ${ }^{\text {"70 }}$

Über seine pädagogischen Intentionen gibt Waldis ebenfalls Auskunft. Die Lieder sollen „belehren“, sie sollen den Unwissenden Informationen über die Zusammenhänge des protestantischen Gottesverständnisses geben. Von Psalm 78 steckt die erste Strophe den Rahmen in exemplarischer Weise ab:

„Merck uff mein volck zu dieser stund,

Und neyget ewre Ohren,

Faßt wol die red auß meinem mund,

${ }^{70}$ Zit. bei Arnold E. Berger (Hg.), Lied-, Spruch- und Fabeldichtung im Dienste der Reformation, Darmstadt 1967, 138f. 
Und wöllet fleissig hören.

Mein mund thu ich in sprüchen auff,

Erzel die alten gschichten,

$\mathrm{Da} \beta$ jr betracht und mercket drauff,

Nach Gottes wort zu richten,

Was wir han ghört,

Verkündn wir jetz wie Gottes wort" ${ }^{\text {"71 }}$.

Als charakteristische Zugabe fällt die Schlußstrophe auf, in 81 von 155 Liedern ist ein solcher Schluß angehängt, weil sie noch einmal die Intention des Dichters verstärkt und in eine doxologische Richtung weist. Als Beispiel sei Psalm 133, 5 zitiert:

„Dafür solln wir jm danckbar sein,

Und seinen Namen loben,

Daß Er allhie sein Christlich gmein,

Gar reichlich tut begoben

Durch Christum werdt, der hier auff erdt,

Ist für uns all gestorben,

Die seligkeyt erworben" ${ }^{672}$.

Im Strophenbau wechseln drei- und vierhebige Verse. Die meisten Lieder haben jambische Messung, bei kreuzweiser und symmetrisch geordneter Reimstellung. Der Wechsel von Hebung und Senkung ist streng durchgeführt. Alle formalen Elemente stehen im Dienst der Aussage- und Wirkabsicht des Autors. Waldis' „Dichtungen greifen ähnlich denen anderer Kirchenliederdichter der Zeit auf ältere Formen volkssprachlicher Dichtung, namentlich des Minnegesangs zurück ${ }^{673}$. Für die 155 Psalmlieder gab es 152 verschiedene Melodien ${ }^{74}$. Über sie wird geurteilt: „tendenziell schlicht und meist syllabisch mit nur gelegentlichen Verzierungen, dabei aber durchaus nicht ohne Anspruch, mit einem oft eine Oktave überschreitenden Ambitus und lebhafter Rhythmik wie Melodik ${ }^{675}$. Auch wenn das Waldis' Werk keine Neuauflage erlebt hat, hat es große Verbreitung in Gestalt von Abschriften und Abdrucken einzelner Psalmen gefunden. Der calvinistische Genfer Reimpsalter (übersetzt von A. Lobwasser, Leipzig 1573) hatte inzwischen im deutschen Sprachraum die Führungsrolle für das geistliche Liedgut übernommen. Gleichwohl sind die Lieder von Burkard Waldis nicht gänzlich vergessen worden. Sowohl im dänischen als auch im schwedischen und im finnischen Gesangbuch sind bis

71 Zit bei Horn (wie Anm. 66), 36.

72 Ibidem, 46.

73 Thomas Schmidt-Beste, Art. Waldis, Burkard, in: Musik in Geschichte und Gegenwart 17 (2007), 394; vgl. auch Horn (wie Anm. 66), 37; 52f.; 64.

${ }^{74}$ Der ganze Waldis-Psalter wurde vom Hofkapellmeister Johann Heugel (1500-1584/5) vier- und fünfstimmig für den Gebrauch am Kasseler Hof vertont.

75 Schmidt-Beste, ibd. 
heute Lieder enthalten, deren Melodien Burkard Waldis zugeschrieben werden ${ }^{76}$. Mehrfache Verweise auf Waldis' Werk finden sich auch in der hymnologischen Forschung Finnlands. Besondere Erwähnung verdient folgendes Detail: Wer das Abendlied „Hinunter ist der Sonnen Schein“ (Evangelisches Gesangbuch 467) kennt, weiß wahrscheinlich nicht, dass Melchior Vulpius nur bedingt Schöpfer der Melodie genannt werden darf. „Vulpius schließt sich in seiner Weise an eine Melodie an, welche Burkard Waldis [..] im Jahre 1553 zu seiner Bereimung des 124. Psalms „Es muß die ganze Christenschar bekennen" schrieb. Vulpius übernimmt die erste Zeile der Psalmweise ganz und richtet sich auch sonst nach ihr" ${ }^{677}$.

1553 konnte Waldis eine Überarbeitung des Buches „Die Ehr und mannlichen Thaten des streitbaren Ritters und Helden Theuerdank", das von Kaiser Maximilian I. stammte, vorlegen. Das Buch erlebte vier Auflagen ${ }^{78}$.

Waldis betätigte sich auch als Übersetzer und trug mit der Übersetzung lateinischer Satiren gegen das Papsttum zur Diskussion und Kontroverse zwischen den Konfessionen bei. Im Auftrag des hessischen Landgrafen übertrug er 1554/55 die große Karikatur „Regnum papisticum“ des Thomas Kirchmair (Naogeorgus) und widmete das Werk Margarethe von der Saale, der Nebengemahlin Philipps. Es folgte eine Übersetzung der „Summarien über die ganze Bibel“ von Rudolph Gualtherus $(1556)^{79}$.

In seinem Amt als Pfarrer genoß Burkard Waldis in Abterode ein hohes Ansehen. Die Gemeinde schätzte es sehr, dass er Gottes Wort in Verkündigung und Seelsorge glaubwürdig vertrat, christlichen Unterricht erteilte und viele Besuche durchführte. Konsequent, loyal und kreativ ist er seiner Berufung nachgekommen. Das Bedauern groß war, als er 1556 erkrankte und seinen Dienst nicht mehr versehen konnte. Waldis ist wahrscheinlich noch im selben Jahr gestorben. Er wurde in Abterode begraben. Sein Grab ist nicht bekannt ${ }^{80}$. Nachfolger wurde sein Schwiegersohn Balthasar Hildebrandt ${ }^{81}$, der ihn bereits in der Krankheitszeit vertreten hatte.

${ }^{76}$ Vgl. Den danske salmebog, Nr. 489. Im „Svenska Psalmboken“ (1986) ist Waldis mit sechs Melodien vertreten, die 13 Liedern zugeordnet wurden; siehe >http://sv.wikipedia. org/wiki/Burkard_Waldis $<$. (Zugriff 02.09.2008).

${ }^{77}$ Handbuch zum Evangelischen Kirchengesangbuch. Sonderband, hrsg. von ARNO BÜChNer/Siegfried Fornaçon, Göttingen 1958, 543. Vgl. Siegrried FornaçOn, Hinunter ist der Sonnen Schein, in: Jahrbuch für Liturgie und Hymnologie 1, 1955, 118ff. - Im Evangelischen Gesangbuch, Ausgabe für die Landeskirchen Niedersachsens, findet sich ein liturgisches Stück von Burkard Waldis, eine Gloria-Patri-Strophe.

${ }^{78} \mathrm{Vgl}$. Buchenau (wie Anm. 28), 36f.

${ }^{79}$ Ibidem, $37 \mathrm{ff}$.

${ }^{80}$ HeLENe BREHM berichtet in ihrem Artikel „Vom alten Abterode“, der 1912 in der Zeitschrift „Hessenland“ erschienen ist: „Man fand bei baulichen Veränderungen, die etwa in der Mitte des vorigen Jahrhunderts am Pfarrhause vorgenommen wurden, im Pfarrhofe, der vielleicht ehemals ein Gottesacker war, da er nahe bei der Kirche liegt, einen Steinsarg. Nach mancherlei Anzeichen deutete man die in ihm enthaltenen menschlichen Überreste als diejenigen von Waldis. Auch wurde eine Grabplatte aufgedeckt, die man wegen der darin eingetragenen Inschrift für den Grabstein seines Schwiegersohnes Hildebrandt hielt".

${ }^{81}$ Er hatte Waldis' Stieftochter Katharina Westermann geheiratet. 
8. Leben und Werk des Burkard Waldis liefern, auch wenn Phasen seiner Biographie im Dunkeln liegen, einen wichtigen Baustein für den geistigen Zusammenhang, der Livland und Kurland mit Hessen verbindet. Als volksnaher Schriftsteller hat Waldis wegweisende Beiträge zur deutschen Literaturgeschichte geliefert. Mit seinen politischen und literarischen Talenten hat er zur Konsolidierung der Reformation in Riga beigetragen. Der Wahlspruch seines Lebens: „mutatio est dexterae excelsi“/Die Rechte des Höchsten kann alles ändern... (Psalm 77, 11) ${ }^{82}$ zeigt ihn als konsequenten lutherischen Theologen. In gereimter Form bringt er seine Erfahrung und Überzeugung in der 99. Fabel des dritten Buches zur Sprache:

\author{
„Wer aber Gott vor Augen hält, \\ nach Tugend, Kunst und Weißheit stellt, \\ aufs höchst befleißt bei Nacht und Tag, \\ wie er seinem Nächsten dienen mag, \\ erlangt zuletzt durch Tugend Fron \\ groß Lob und Preis, der Ehre Kron“ (Esopus III 99) ${ }^{83}$.
}

Von 1945 bis 1950 gab es in der Bad Sooden-Allendorf eine Burkard WaldisBuchhandlung. Noch heute erinnert in der Stadt eine um 1880 nach Burkard Waldis benannte Straße an den Franziskaner, Zinngießer, Dichter und Pfarrer.

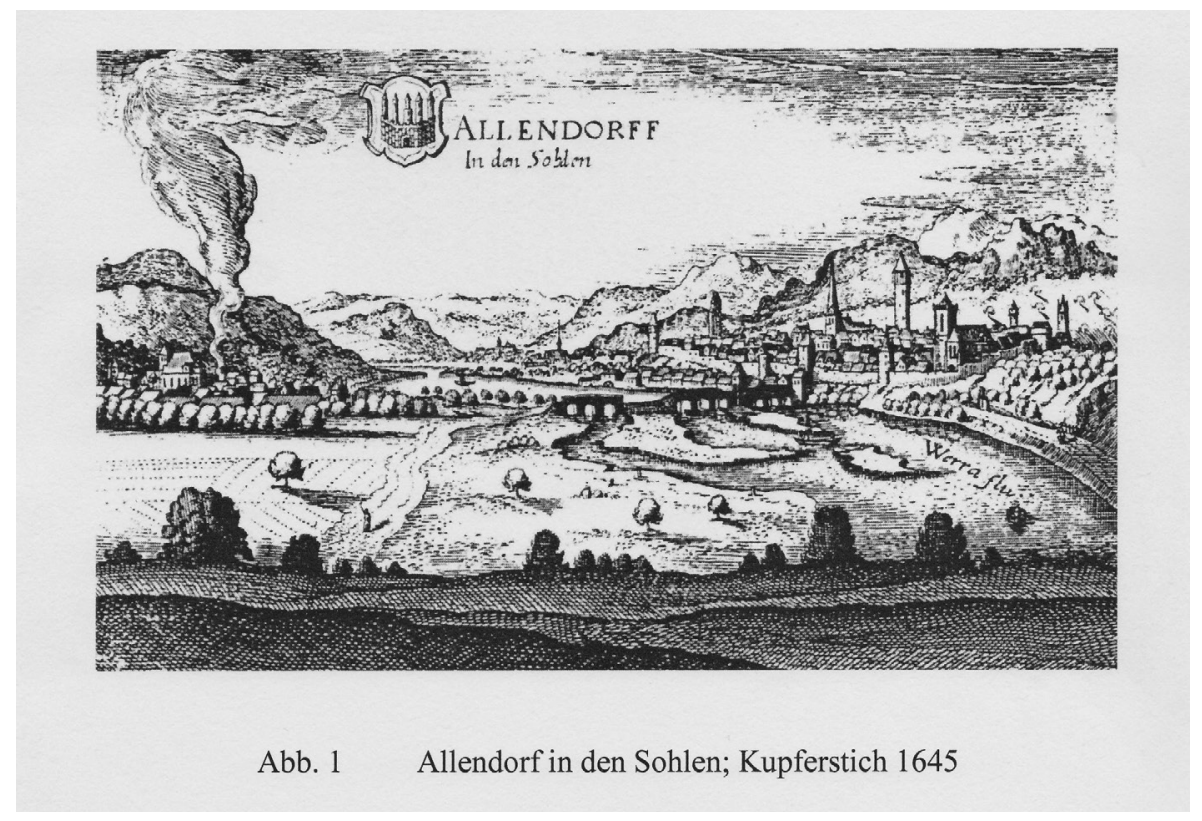

${ }^{82}$ Diese Übersetzung wird von Bezzenberger (wie Anm. 30) und Burmeister (wie Anm. 58) vorgeschlagen. Bei Luther heißt es hingegen: „Darunter leide ich, dass die rechte Hand des Höchsten sich so ändern kann".

${ }^{83}$ Vgl. Kurz (wie Anm. 3), 416. 

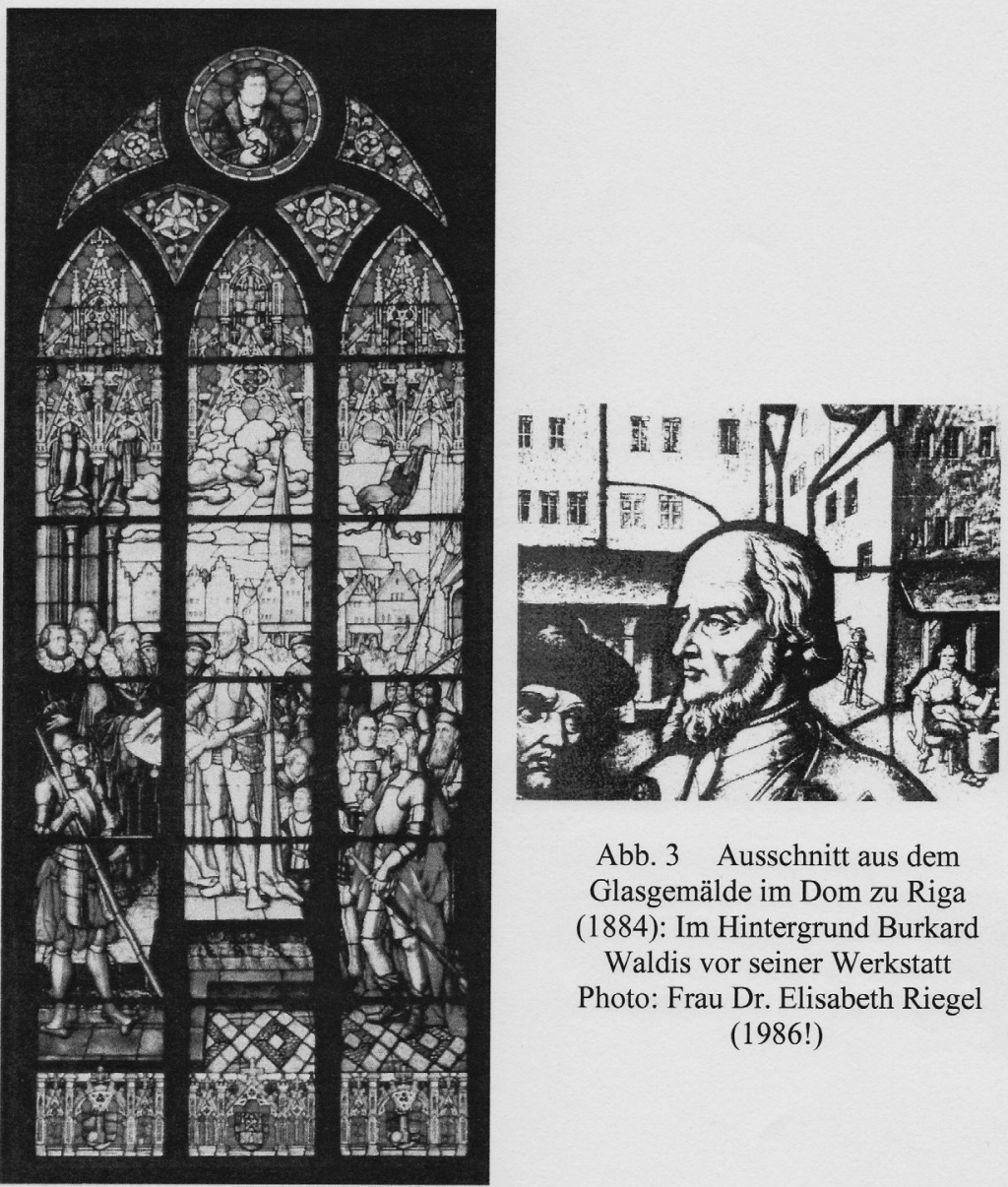

Abb. 3 Ausschnitt aus dem Glasgemälde im Dom zu Riga (1884): Im Hintergrund Burkard Waldis vor seiner Werkstatt Photo: Frau Dr. Elisabeth Riegel (1986!)

Abb. 2 Glasgemälde im Dom zu Riga (1884); Anton Dietrich (18331904), Werkstatt von Hans Mayer/ München: Der Meister des Livländischen Ordens, Wolter von

Plettenberg, erteilt der Stadt Riga das Recht zur freien Religionsausübung (1525). Aus: Janis Lejnieks/Indrikis Sturmanis, Unterwegs in Lettland, Rostock 1992, 16 


\section{Bircoortins Woldis}

Abb. 4 Autograph von Burkard Waldis

Archiv der EKKW Kassel, Fundkartei Abterode 1544-49, 1. Bd.
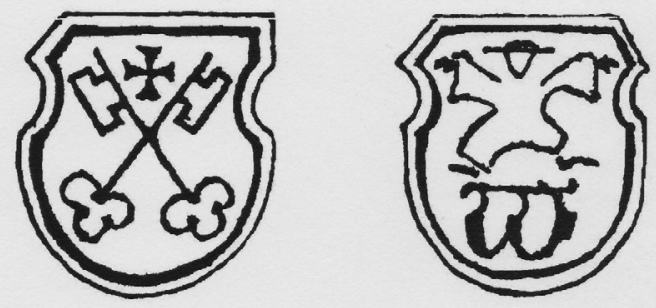

Abb. 5 Zinnmarken: Stadtzeichen der Stadt Riga; Meisterzeichen des Burkard Waldis

Aus: Karl Steinbach/Elisabeth Riegel,

Burkard Waldis aus Allendorf an der Werra,

in: Das Werraland 39, 1987, $1 \mathrm{ff}$

(nach Johannes Gahlnbäck 1924) 


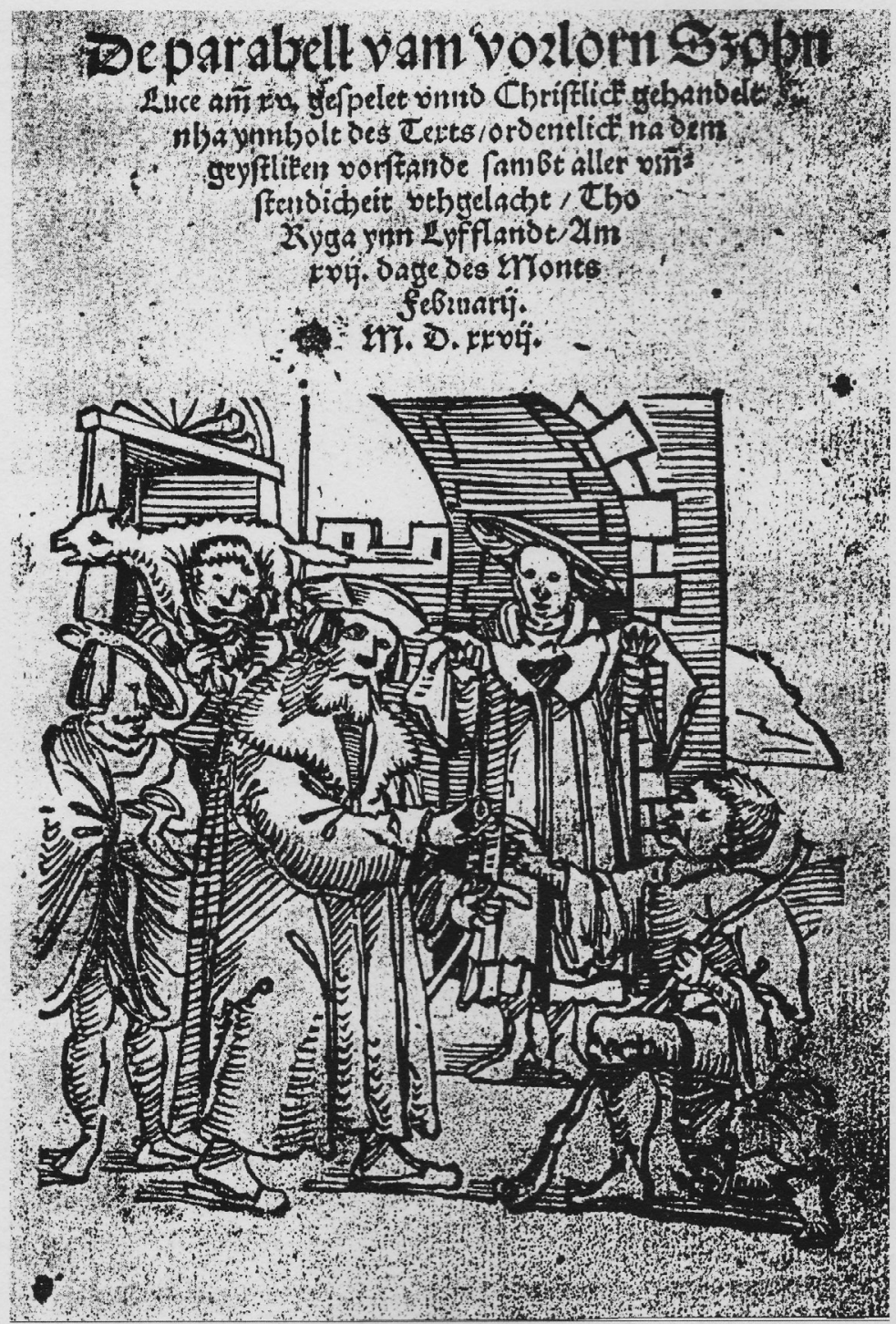

Abb. 6 Titelholzschnitt „Der Verlorene Sohn“ (1527)

Aus: Otto Pohrt, Reformationsgeschichte Livlands.

Ein Überblick, Leipzig 1928, $133 \mathrm{f}$ 


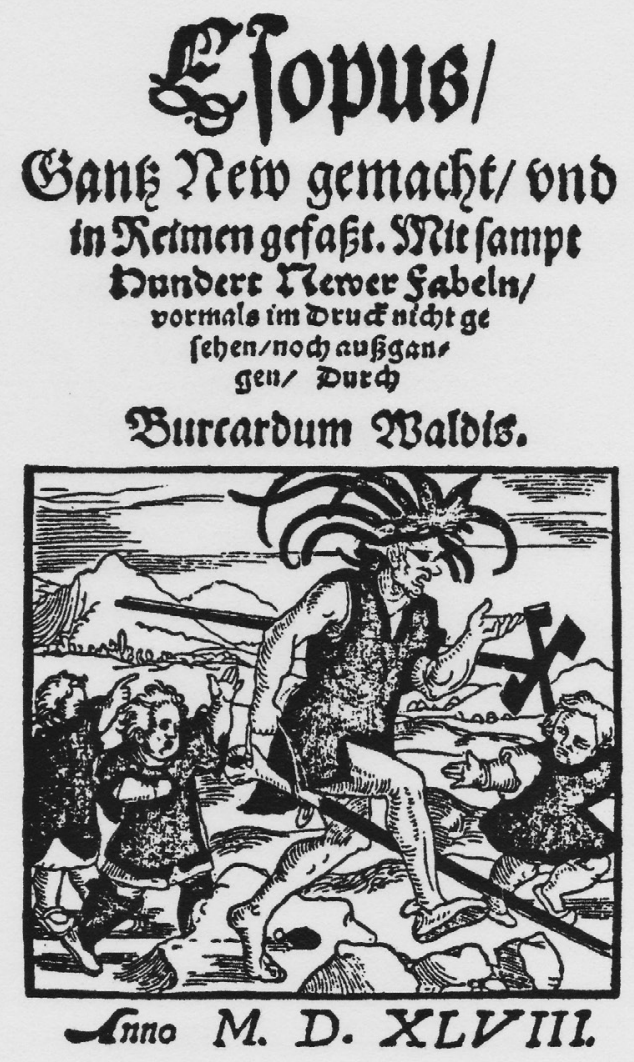

Abb. 7 Titelblatt der ersten Ausgabe von Burkard Waldis' „Esopus“, Frankfurt 1548 Aus: Günter E. Th. Bezzenberger, Burkard Waldis. Mönch, Zinngießer, Pfarrer und Dichter, Kassel 1984, 65 


\section{2er\$g In?lewe (bejange woifel Dho tünfliche Kreimen gebzade/ ourd Collegi Soriestatis gesu her bi polj

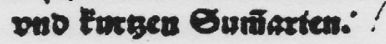

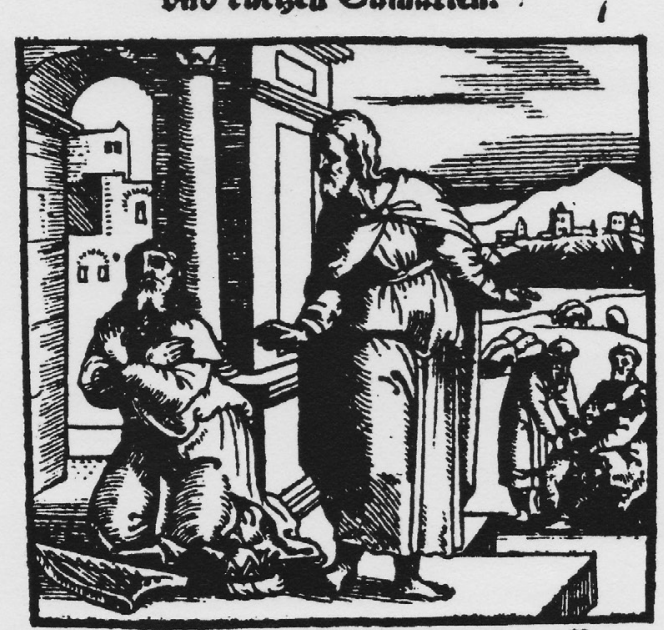 \\ รu Standfurt/25ci cha. Égendli,}

Abb. 8 Titelblatt der ersten Ausgabe des Psalters, Frankfurt 1553 Aus: Günter E. Th. Bezzenberger, Burkard Waldis. Mönch, Zinngießer, Pfarrer und Dichter, Kassel 1984, 89 


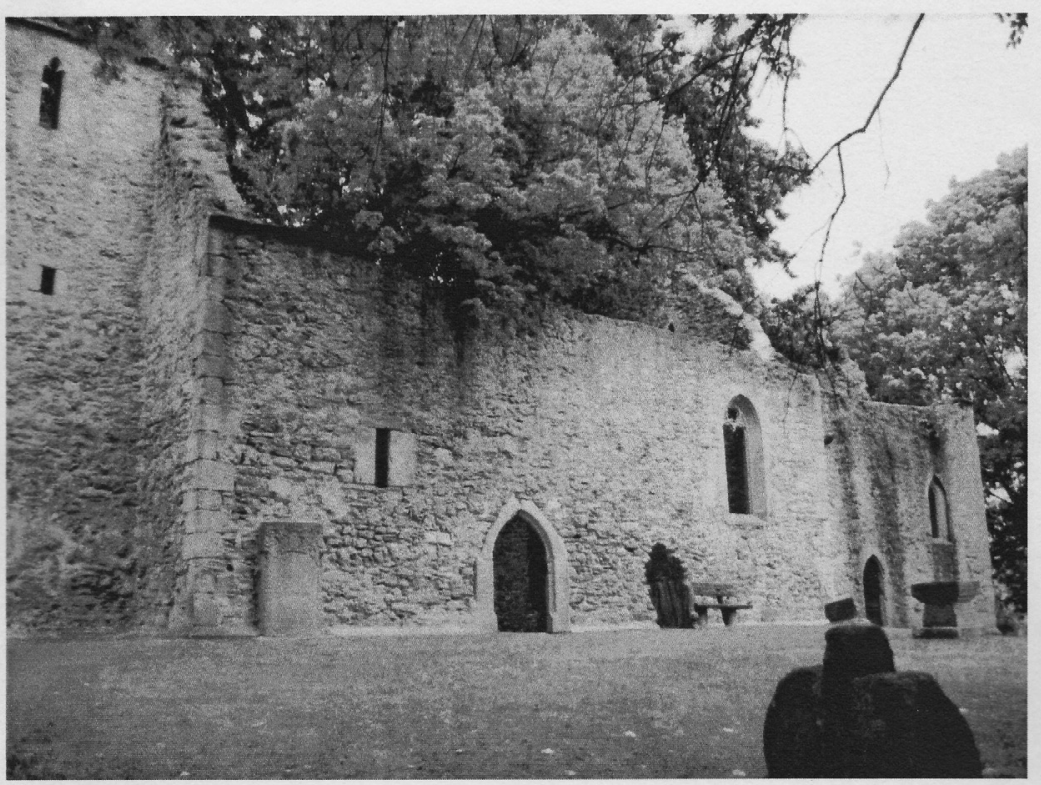

Abb. 9 Ehemalige Pfarrkirche von Abterode; seit 1809 Ruine

Photo: Ulrich Schoenborn, Marburg 2008 